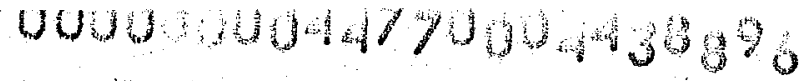

$$
\begin{array}{cc}
4<-25 \\
\operatorname{LBL}-5770 & a-1
\end{array}
$$

\title{
LIQUID PHASE SINTERING OF IRON WITH COPPER \\ BASE ALLOY POWDERS
}

Meng-Hsiu Chen

(M. E. thesis)

December 1976

Prepared for the U. S. Energy Research and

Development Administration under Contract W-7405-ENG-48

\section{For Reference}

Not to be taken from this room

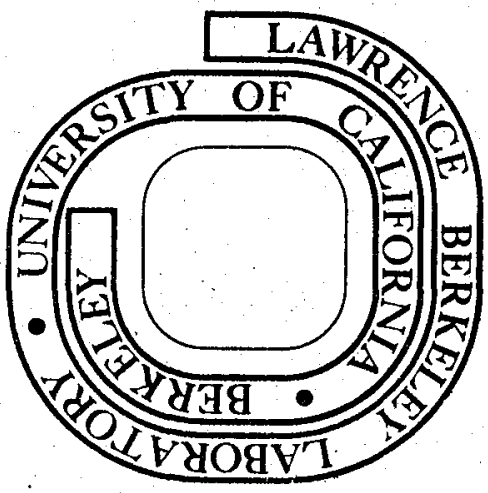


This report was prepared as an account of work sponsored by the United States Government. Neither the United States nor the United States Energy Research and Development Administration, nor any of their employees, nor any of their contractors, subcontractors, or their employees, makes any warranty, express or implied, or assumes any legal liability or responsibility for the accuracy, completeness or usefulness of any information, apparatus, product or process disclosed, or represents that its use would not infringe privately owned rights. 


\section{Liquid Phase Sintering of IRon With Copper BASE AlloY POWDERS}

\section{CONTENTS}

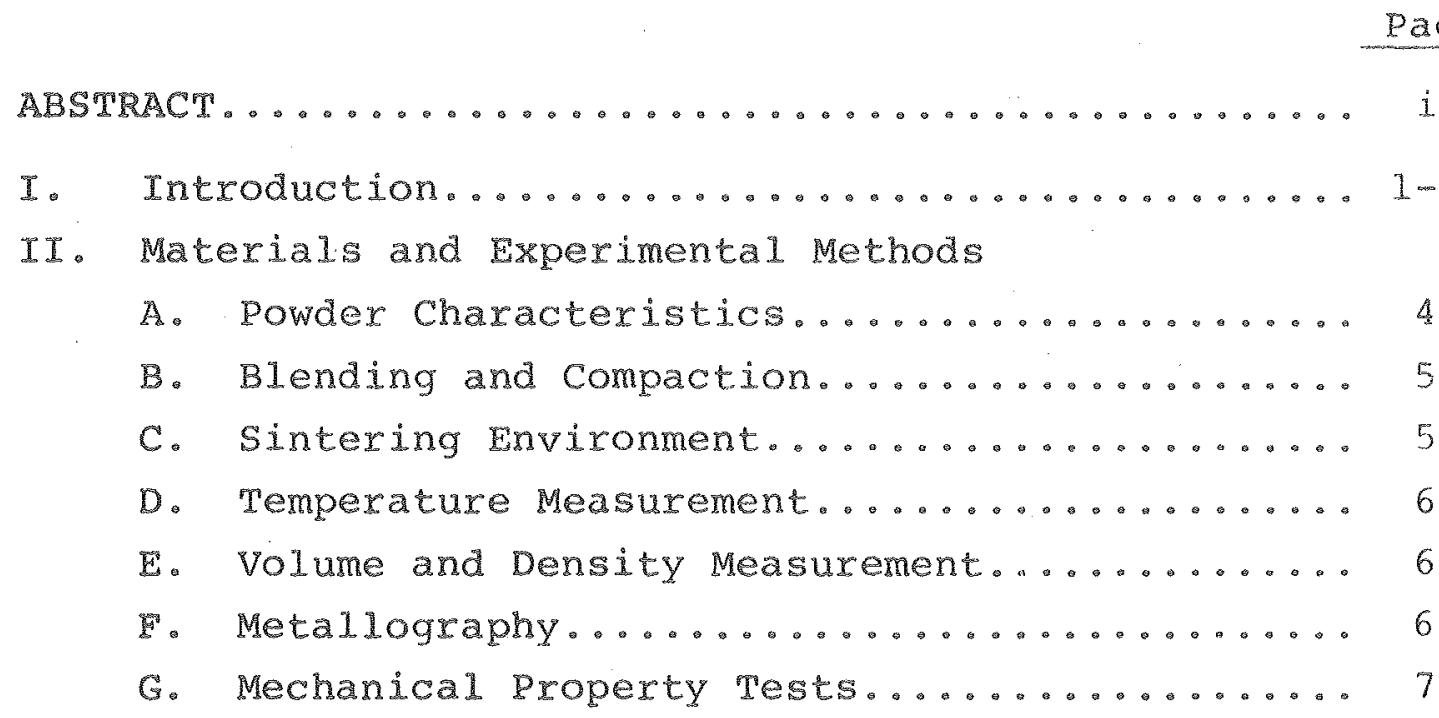

III. Results and Discussion

A. Densification......................... 9

B. Tensile and Transverse Rupture strength...... 10

C. Microhardness.......................... 11

D. Microscopic Examination.................... 13

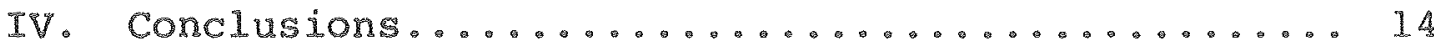

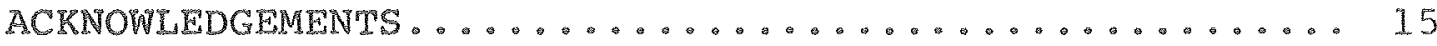

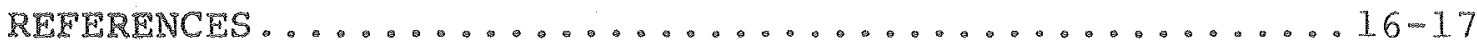

FIGURE CAPTIONS. ............................ 18-19

FIGURES ................................ 20-38 


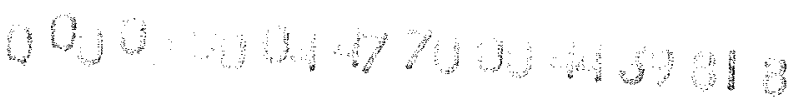

Liquid Phase Sintering of Iron with Copper

BASE AlLoY POWDERS

\author{
By \\ Meng-Hsiu Chen \\ Materials and Molecular Research Division \\ Lawrence Berkeley Laboratory \\ and Department of Mechanical Engineering \\ University of California \\ Berkeley, California 94720
}

\begin{abstract}
The physical and mechanical properties of a series of atomized elemental $\mathrm{Fe}$ and prealloyed $\mathrm{Fe}+\mathrm{Cu}$ powders blended with different amounts of liquid phase additions were studied in the as-sintered condition.

The alloy of $88 \% \mathrm{Cu}, 3 \% \mathrm{Mn}, 9 \% \mathrm{Si}$ was found to have superior characteristics for use as a liquid phase material in the sintering of elemental Fe or its prealloyed powders. The effects of additions of this alloy on the sintered density, tensile strength, transverse rupture strength and hardness were determined and compared with other reported results.

The sintexing mechanism and swelling effect did not conform with conventional theories. Some recommendations are made for further studies in liquid phase sintering of ferrous systems.
\end{abstract}





\section{INTRODUCTION}

The primary objective of this study was to develop a Low melting master alloy material to be used as a liquid phase in the sintering of Fe compacts. In the simple process of pressing and sintering, a compact without the presence of some liquid phase can only reach a sintered density of about $90 \%$ of theoretical. It has been found that the regidual porosity has many deleterious effects on the mechanical properties of parts made by powder metallurgy techniques. other processes to produce high density parts such as high compacting pressure, forging, hot isostatic pressing, sintex-xepress-resinter and infiltration axe all comparatively higher in cost or involve more elaborate procedures. Therefore, a need exists for an improvement in the simple presssinter techniques to achieve bettex density and strength. Liquid phase sintering could be a simple way to satisfy this need.

Copper and copper base alloys have been widely used in the industry either as a base material or as an infiltrant for ferrous components. Mixtures of ixon and copper powders are commonly used to produce high strength steel parts. Copper powders, at supersolidus sintering temperatures, melt and wet the ixon particles and bind them tightly together after solidification. The sintering behavior of Fe+Cu alloys made from mixed elemental powders has been well documented by many authors since $1946^{1-6}$ A disadvantage of 
copper additions is "copper growth" (swelling) during sintering which reduces the sintered density and dimensional accuracy. The cause and the effect of this phenomenon have also been extensively studied. G. Bockstiegel" 8 and T. Krantz ${ }^{9}$ have given a good review on this subject. However, a controversy still remains in the interpretation of the cause of the "copper growth" in Fe+Cu mixtures. Investigators believe swelling is caused by (i) volume diffussion of copper into iron particles, (ii) penetration of liquid copper between the ixon particles, or (iii) penetration of molten copper into the grain boundaries of the iron particles. Recently, Berner, Exner and Petzow, 10 Trudel and Angers, 11 concluded that the "copper growth" is too rapid to be caused by volume diffusion and proved that the rapid expansion observed at the melting point of $\mathrm{Cu}$ is caused by the penetration of copper in the boundaries within and between Fe particles. Pure copper has a melting temperature of $1083^{\circ} \mathrm{C}$ : therefore, a higher temperature is required for the molten copper to wet and flow freely through the interconnected pores in the pressed compacts. After studying the copper base binary and ternary phase diagrams, it was found that some alloys have much lower melting temperatures, e.g. $870^{\circ} \mathrm{C}$ for Cu-Mn and $858^{\circ} \mathrm{C}$ for $\mathrm{Cu}-\mathrm{Si}$. The temperature of the peritectic reaction, $\alpha+\operatorname{melt} \geqslant \beta\left(852^{\circ} \mathrm{C}\right.$, $\checkmark 5.25 \% \mathrm{Si})$, decreases suddenly to $760^{\circ} \mathrm{C}$ upon the addition of $2.58 \mathrm{Mn}^{12}$ In a search for a material that would alloy 
rapidly during short sintering cycles and would be compatible with existing equipment and practices, it was found from this study that the system of Cu-Mn-si offered many advantages such as a low melting point, fast diffusion rate, and greater hardenability. In the present study, an alloy composed of $88 \%$ Cu, 3 Mn and $98 \mathrm{si}$ was chosen as an additive to provide a liquid phase during sintering. For brevity, this composition will be referred to as Cu-Mn-Si. It is an intermetallic compound that melts at $780^{\circ} \mathrm{C}$. 


\section{II: MATERIALS AND EXPERIMENTAL METHODS}

\section{A. Powder Characteristics:}

Characteristics of the elemental and prealloyed powdexs used in this study are shown as manufacturer's data in the following table.

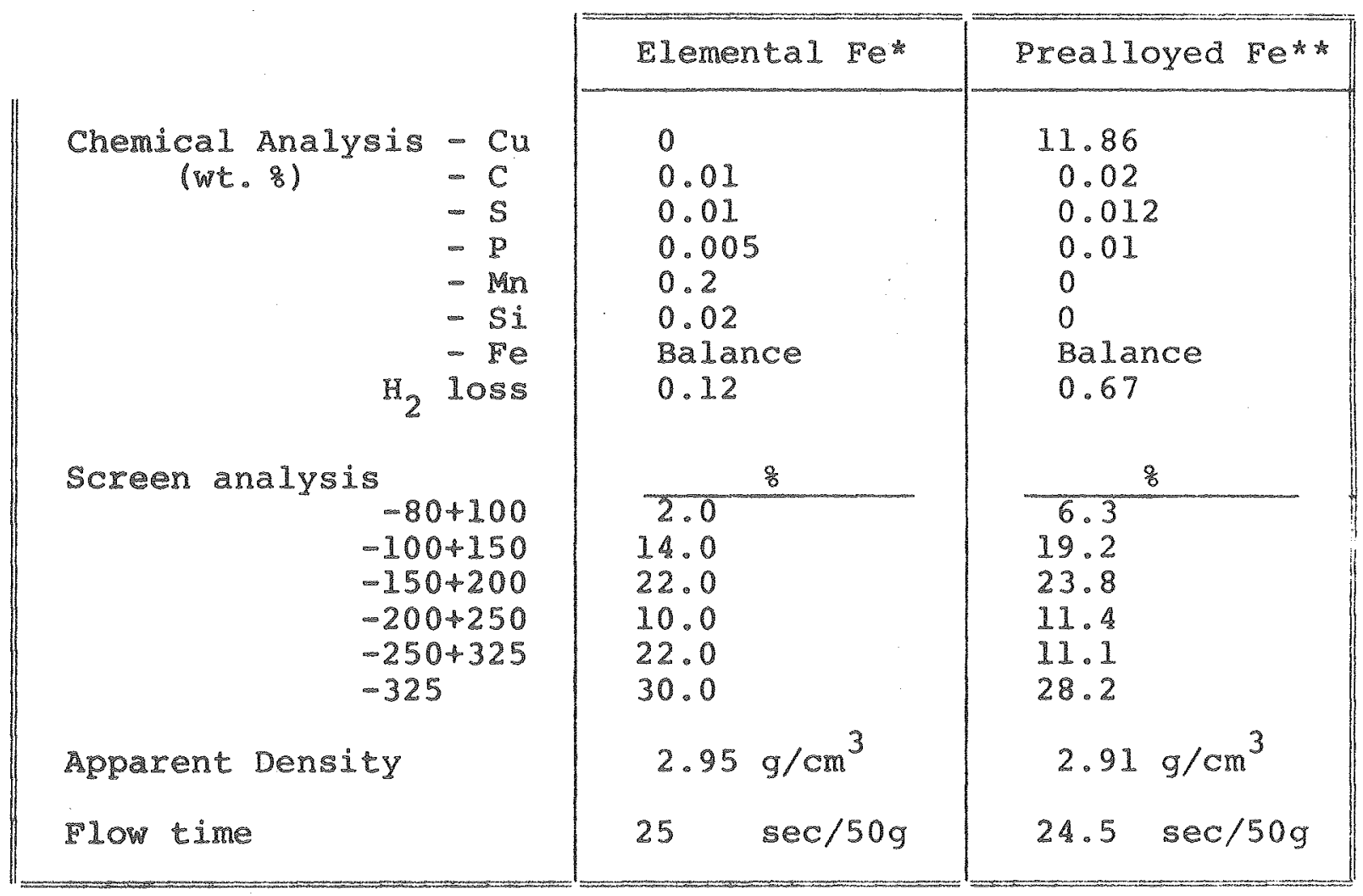

* EM atomized, grade 300M, A. O. Smith Company

* Preinfiltrated. Prefiltron 12. Pfizer Company 
The above two powders were chosen because of their similarity In particle size distribution and physical properties. The Cu-Mn-Si alloy was cast into an ingot which was crushed and then ball milled to $1 \sim 8 \mu$ size. X-ray examination showed the alloy to be an intermetallic compound with a structure similar to $\mathrm{Cu}_{3} \mathrm{si}$. The compound had a silvery luster and was very brittle in spite of the large cu content. The measured density was $7.85 \mathrm{~g} / \mathrm{cm}^{3}$.

B. Slending and Compacting

Carefully weighed powders, together with alumina pellets, were contained in glass jars and tumble blended for sixty minutes. The alumina pellets sufficiently broke up agglomeraced powders and aided in producing a uniform powder mixture. Figure 1 shows a pressed compact with fine Cu-Mn-Si powders we11 distributed around coarse Fe particles. After blending. each mixture of powders was pressed in a double acting steel die, using a hydraulic press. Every compact was held under pressure over two minutes to allow for outgassing. All die surfaces were Iubricated before each compacting process. The lubricant used was a mixture of 1009 of $z$ inc stearate in one liter of methylchloroform (1.1.1-txichloroethane).

\section{Sintering Envixonment}

A11 samples after compacting were sintered in a hydro gen furnace (Fig.2). A Matheson 8362 purifier operating at $725^{\circ} \mathrm{F}$ was used to purify the $\mathrm{H}_{2}$ before it went into the furnace. Purified $\mathrm{H}_{2}$ provides a good reducing atmosphere for sintering and excludes the carburization effect by the 
co content in other available sintering atmospheres. ${ }^{13}$ To assure that the fresh flowing $\mathrm{H}_{2}$ was in contact with the sample surfaces, the compact was put in a cylinarical crucible with meshed ends and the furnace was pressurized to $6 \sim 8$ psi over atmospheric pressure. Some sinterings were performed in a closed bottom crucible which resulted in a noncirculating atmosphere at the bottom of the crucible and thus left some visible oxides on the sample surfaces after sintering. This suggests that the positioning of compacts during sintering must be carefully designed to allow a good fresh flowing atmosphere all over the sample surfaces.

\section{Temperacure Measurement}

A Chromel-Alumel "Type $K "$ thermocouple sealed in a protection tube was used to measure the sintering temperature. This themocouple was set at the midale of the furnace hot zone together with the sample during the entire sintering period.

A digital indicator $\left(\right.$ Type $\left.\mathrm{K} /{ }^{\circ} \mathrm{C}\right)$ was used to read the temperature and an $x-y$ recorder was used to calculate the heating and cooling rate, and to determine the melting point of the liquid phase.

\section{E. Volume and Density Measurement}

A volume displacement method was used to measure the volume and density of the green or sintered compacts. Before immersing the compacts in the water they were first 
vacuum impregnated with epoxy resin which filled up the poxes to prevent the penetration of water into the compacts.

During immersion, the compacts were suspended with a thin wire. The interaction between the suspension wire and the wher's surface, resulting from surface cension, influenced the weight measurement of the immersed compacts. A few drops of kodak 200 Photoflow solution added to $100 \mathrm{ml}$ of watex eliminated the problem. ${ }^{14}$ other volume measurements done using a micrometer resulted in close agreement (within $\pm 0.05 \mathrm{~cm}^{3}$ ) with the aforementioned measurements. F. Metallography

A11 samples prepared for metallographic examination Were mounted with Koldmount self-curing resin powder. After the mounting resin solidified, the samples were abraded on sillon carbide papers down to 600 grit, carefully polished on a $1 \mu$ diamond whee 1 , and micropolished in a $0.05 \mu$ alumina SIUITY.

This technique gave satisfactory resolution of the polished surface at $1000 \%$ under the optical microscope. A 28 Nital etch was used before examination. The vacuum impregnation by epoxy resin, previously used for accurate volume measurements, also prevented small particles on the surface of the sample from being pulled out during polishing. If epoxy had not been used, voids from small particles leaving the surface could have caused false porosity measurements. However, during examination with the scanning electron 
microscope, the nonconductive epoxy in the pores would be charged by the electron beam and cause the fluorescent emmission to degrade the contrast of the picture. Samples were also prepared for hot stage scanning electron microscopy to directly observe the formation and flow of the liquid phase during sintering. Electron microprobe analysis was used to investigage the distribution of each alloying element in the sintered compact.

\section{G. Mechanical Property Test}

Sintered tensile test bars conforming to MPIF standard 10-63, Fig. 3, were tested with an Instron testing machine using a crosshead speed of $0.05 \mathrm{~cm} / \mathrm{min}$. AstM standard $\mathrm{E} 8$ was used to choose gripping devices and methods of determining tensile strength and elongation. Transverse cupture test bars conforming to MPIF standard 13-62, Fig. A were also tested with the Instron testing machine using a three point bending Eisture, Fig. 5. A Leitz Wetzlar miniload hardness tester was used to determine the hardness of the sintered parts. 


\section{II: RESULTS AND DISCUSSIONS}

\section{A. Densification}

The effect of $\mathrm{Cu}-\mathrm{Mn}-\mathrm{Si}$ content on the green density of Fe compacts is shown in Fig. 6. The decrease in the green density at higher Cu-Mn-Si additions in the EMP elemental Fe powder compacts was due to the incompressibility of the Cu-Mr-Si. This can be explained by the high hardness (630VH) of the intemetallic compound. Because of the varying green density, the densification results could be compared either to the compacting pressuxe or to the green density. Shown in Figs. 7, 8 and 9 , axe the effects of different Cu-Mn-Si additions on the sintered densities under different compacting pressures. Figures 10, 11 and 12, show green density vs. sintered density with different Cu-Mn-Si additions. Combining the above results, it was found that densification happened most effectively at a sintering temperature of about $1150^{\circ} \mathrm{C}$. Figure 13 shows the temperature effects on sintered densities. In this igure, the samples were compared based on identical green densities of $6.0 \mathrm{~g} / \mathrm{cm}^{3}$ without considering their compacting pressure. The increasing density at increasing liquid phase addition resembles the Fe + Cu system reported by many authors, but with a higher degree of densiEjcation at the same amount of addition and the same sintering condition. A swelling of the compacts occurred when sintexing with $10 \%$ Cu-Mr-si or less. This is very similar to the "copper growth" in the elemental Fe - Cu system. The 
densification results of sintering prealloyed Fe - Cu powder compacts with various amount of Cumn-Si additions are shown in Fig. 14. In this prealloyed system, the "swelling" phenomenon did not appear because the powders were already saturated with copper. The copper prevented the penetration of molten liquid into the grain boundaries and limited further diffusion of copper into iron particles, thus eliminating the cause of "swelling". A good densifcation result of 99 of the theoretical density was achieved by sintering: 1) EMP Fe and $300^{\circ} \mathrm{Cu}-\mathrm{Mn}-\mathrm{Si}$ at $1050^{\circ} \mathrm{C}$ for four hours in a $\mathrm{H}_{2}$ atmosphexe: 2) EMP Fe and $400^{\circ} \mathrm{Cu}-\mathrm{Mn}-\mathrm{Si}$ at $1150^{\circ} \mathrm{C}$ for one hour: 3) EMP Fe and $300^{\circ} \mathrm{Cu} M-\mathrm{Mi}$ at $1350^{\circ} \mathrm{C}$ for five minutes, or 4) prealloyed powder and $108 \mathrm{Cu}-\mathrm{Mn}-\mathrm{Si}$ at $1150^{\circ} \mathrm{C}$ one hour.

B. Tensile Strength and Transverse Rupture Strength

The tensile test specimens were compacted at a relativeIy low pressure of $60 \mathrm{ksi}$. Knowing from the above discussions that higher densities and thus better properties were achieved by increasing the compacting pressure or green density, the tensile strength can be expected to be higher than the data presented here. From Fig. 15, it can be seen that the tensile strength of EMP Fe compacts increased with increasing Cu-Mn-Si concent up to a limit of about $20 \%$ and then leveled off. Further increases in liquid phase content increased the sintered density but not the tensile strength. The tensile strength of the prealloyed powder compacts was increased extensively by the addition of Cu-Mn-Si and reached a masimum at about $10 \%$ 
wt. content. More Cu-Mn-Si increased the sintered density but decreased the ultimate tensile strength. This may appear to be contradictory to the conventional assumption of increasing mechanical properties with increasing density. However, care must be taken when making a comparison. The assumption held txue when comparing samples of the same material compositions. A shift in composition may have had a weakening effect large enough to overcome the strengthening effect of highex density. This is shown by the dxop of ultimate tensile strength and transverse rupture strength in a prealloyed powder compact with more than $108 \mathrm{Cu}-\mathrm{Mn}-\mathrm{Si}$ content. Transverse rupture test specimens were sintered at the same conditions as the tensile specimens, but a higher compacting pressure of $80 \mathrm{ksi}$ was used. The results are shown in Fig. 16. The transverse rupture strength of EMP compacts also increased with increasing $\mathrm{Cu}-\mathrm{Mn}-\mathrm{Si}$ content up to about 20 \% and then leveled off as in the case of tensile strength. The prealloyed powdex compacts also showed a maximum of T.R.S. at about $10 \%$ Cu-Mn-Si addition and then started to decrease with largex additions. A careful analysis showed that all the mechanical properties reached a maximum at about $20 \%$ total copper content.

\section{Mcroharaness}

By using a Leitz miniload haxdness tester with a 50 gram load the hardness of EMP iron particles in the green com pact $120 \mathrm{VH}$. The pure EMP compacts after: 
sintering had an annealed haxdness of 64 VH which is considered typical for a very soft and ductile material. Cu-Mn-Si had a much higher hardness of 678 VH as may be expected for an intertermetallic compound. The soft EMP powder was miked with some hard Cu-Mn-Si powder and sintered at a temperature high enough to melt the Cumn-si. During sintering, diffusion and solution-precipitation took place. Iron particles were solution strengthened by dissolving most of the silicon and a limited amount of copper and manganese. This resulted in strong particles with a hardness of 465 VH. The originally hard Cu-Mn-Si was softened by losing most of its silicon content and some of its copper and manganese to iron. The result was a soft matrix of $106 \mathrm{VH}$. The final sintered compact consisted of hardened $F e$ particles bonded by a soft copper base matrix. This is a desirable structure for parts as-sintered and good base structure for further forging ${ }^{15}$ or additional processing. The detail composition and hardness in each phase after sintering is shown in Fig. 17 .

\section{Microscopic Examination}

A hot stage electron microscope was used to study the Iiguid phase behavior during sintering by dixect observation. A green compact of Fe - $30 \%$ Cu-Mn-Si was subjected to a heating rate of $12^{\circ} \mathrm{C} / \mathrm{min}$ under vacuum in the hot stage. Before reaching $780^{\circ} \mathrm{C}$, only thermal expansion was noticed because all the particles kept their relative positions, but with increased distances between each other. Above $780^{\circ} \mathrm{C}, \mathrm{Cu}-\mathrm{Mn}-\mathrm{Si}$ particles 
started to melt and the liquid phase fraction increased with temperature. During this stage, the pore size, shape, and distribution started to change. The drastic rearrangement and shrinkage happened only upon complete melting of the Cu-Mn-Si paxticles at $1020^{\circ} \mathrm{C}$. At this temperature, the Fe particles no longer kept their relative positions and all the pores closed in less than 10 seconds. Small shiny flakes of oxides could be observed floating on the liquid surface.

The reaction between Fe particles and the alloying elements was studied by using electron microprobe analysis. Figures 18 and 19 show the microstructure of two samples sintered for five minutes and four hours respectively at $1150^{\circ} \mathrm{C}$ in a $\mathrm{H}_{2}$ atmosphere. Both samples have three different phases present. From the EDAX X-ray profile analysis (Fig. 17), it found that during sintering the diffusion process and boundary penetration were nearly completed within five minutes. The longer sintering time contributed to particles rearranging, and pores closing, spheroidizing and coalescing. The fact that diffusion and boundary penetration happen before rearrangement indicates the reverse of the conventional theory of liquid phase sintering, 16 which assumed that the rearrangement is the Eirst stage before the solution-reprecipitation or diffusion process. 


\section{CONCLUSION}

1. High sintered density of $7.82 \mathrm{~g} / \mathrm{cm}^{3}$ lover 998 of the theoretical value) can be achieved in the sintering of EMP iron compacts by adding Cu-Mn-Si as a liquid phase. If pxealloyed Fe - Cu is employed as a base, similar densification can be achieved by adding only 10 \% Cu-Mn-Si and sintering at $1150^{\circ} \mathrm{C}$ for one hour in $\mathrm{H}_{2}$ atmosphere.

2. The fast diffusion of silicon and some limited amount of copper and manganese into iron particles contributes to better mechanical properties through solution strengthening. The ultimate tensile strength and txansverse rupture strength increase markedly with the addition of $\mathrm{Cu}-\mathrm{Mn}-\mathrm{Si}$ to both elemental and prealloyed iron compacts. Maximum strengths occur at about $20 \%$ total copper content. The compacts made from prealloyed powder have substantially greater tensile and transverse rupture strengths. A tensile strength of $102 \mathrm{ksi}$ and a transverse rupture strength of $188 \mathrm{ksi}$ can be obtained from the prealloyed compacts.

3. Swelling of compacts is observed during sintering of EMP elemental iron compacts with Cu-M-Si additions up to $10 \%$. This is very similar to the "copper growth" observed with elemental iron and copper mixtures. The only difference is that Cu-Mn-Si diffuses very rapidly. Therefore, both diffusion and boundary penetration contribute to the "swelling" of the compacts.

4. The resulting structure of hardened ixon particles bonded by a soft copper base matrix is very desirable for asmintered parts. 
5. Manganese and silicon are beneficial alloying elements in steel design. Theix contributions in regard to heattreatability can be expected to improve the mechanical properties reported in this study.

An investigation of optimal addition of $\mathrm{Cu}-\mathrm{Mn}-\mathrm{Si}$ and heat treatability is recommended for further studies in this axea.

\section{Acknowledgement}

The author is sincerely grateful to prof. Milton $R$. Pickus for his advice and guidance throughout the project. Special thanks to Dx. John Ling-Fai wang for his patient encouragement and valuable direction which contributed substantially to this report. The technical assistance rendered by Mr. John T. Holthuis and Mr. John A. Jacobsen and the many people within the Materials and Molecular Research Division is greatly appreciated.

This work was performed under the auspices of the U.S. Energy Research and Development Administration through the Materials and Molecular Research Division, University of California, Berkeley California. 


\section{REFERENCES}

1. V. N. Eremenko and $Y, V$. Naidich, "Liquid-Phase Sintering", (a special research report) (1970).

2. F. C. Kelley, Iron Age, 158, 57 (1946).

3. L. Northcott and C. J. Leadbeater, "Sintered Iron Copper Compacts", Symposium on Powder Metallurgy - The Iron and Steel Inst. Spec. Report, 38, 142 (1947).

4. J. F. Kuzmick and E. N. Mazza, "Studies on Control of Growth of Shrinkage of Iron - Copper Compacts Duxing Sintering" J of Metals, 188, 1218 (1950).

5. P. U. Gummeson and L. Fross, "How Dimensions and Properties are Affected by Adding Copper to Iron Powdex Compacts" Proc.11th Ann. Meeting Metal Powder Assoc., 56. (1955)。

6. 3. E. Elliot, "Metallurgia", 59, 17 (1959).

7. G. Bockstiege1, "Nature and Cause of Volume Changes in the Sintering of $\mathrm{Fe}-\mathrm{Cu}$ and $\mathrm{Fe}-\mathrm{Cu}-\mathrm{C}$ Powder Compacts", Stahl und Eisen, 79, 1187 (1959)。

8. G.Bockstiege1, "Metallurgia", III (8),67 (1962)。

9. T. Krantz, "Effect of Density and Composition on the Dimensional Stability and strength of Fe-Cu Alloys", Int. Jo of $P / M, 5$ (3), (1969)。

10. D. Berner, H. E. Exner and G. Petzow, "Swelling of FeCu Mixtures During Sintering and Infiltration", Modern Development in P/M, 6, 273 (1973)。

11. Y. Trudel and R. Angers, "Properties of Fe-Cu Alloys Made from Elemental or Prealloyed Powders", 11 (1), 5 (1975)。 
12. C. S. Smith and w. R. Hibbard, Trans. Amer. Inst. Min. Met. Eng. 147, 222 (1942).

13. L. A. Zagorski and E. J. Eckel, "The Effect of the Furnace Atomsphere on the Infiltration of Fe-Cu Compacts" " Int. K. of $P / M, 7$ (2), 11 (1971).

14. J.KLein, (M.S. Thesis), "A Preliminary Investigation of Liquid Phase sintering in Ferrous Systems" MMRD-LBL, Dept. of Mech. Eng. U.C. Berkeley, (1975).

15. H. E. Fischmeister and L-E. Larsson, "Fast Diffusion Alloying for Powder Forging Using a Liquid Phase" " Powder Metal1urgy, 17 (33), 227 (1974)。

16. H. S. Cannon and F. V. Lenel, "Some Observations on Mechanism of Liquid Phase Sintering" "Plansee Seminar 1952,F. Benesovgky (Ed.), Metallwerk Plansee, Reutte, $106(1953)$ 


\section{FIGURE CAPTIONS}

Fig. 1. Green compact of course Fe particles mixed with $30 \%$ Eine Cu-Mn-Si powders.

Fig. 2. Schematic diagram of hydrogen Eurnace.

Fig. 3. MPIF standard 10-63 tensile test specimen.

Fig. 4. Die and punches for making MPIF standard 13-62 transverse rupture test specimens.

Fig. 5. Fixture for transvexse rupture test.

Fig. 6. The effect of Cu-Mn-Si additions to elemental iron on green density at different compacting pressures.

Fig. 7. The effect of $\mathrm{Cu}-\mathrm{Mn}-\mathrm{Si}$ content on sintered density. $\left(1050^{\circ} \mathrm{C}\right)-$ Elemental ixon.

Fig. 8. The effect of $\mathrm{Cu}-\mathrm{Mn}-\mathrm{Si}$ content on sintered density. $\left(1150^{\circ} \mathrm{C}\right)$ - Elemental iron.

Fig. 9. The effect of Cu-Mn-Si content on sintered density. $\left(1250^{\circ} \mathrm{C}\right)$ - Elemental ixon。

Fig. 10. Sintered density vs. green density for compacts sintered at $1050^{\circ} \mathrm{C}$. Elemental iron.

Fig. 1. Sintered density vs. green density for compacts sintered at $1150^{\circ} \mathrm{C}$. Elemental iron.

Fig. 12. Sintexed density vs. green density for compacts sintered at $1250^{\circ} \mathrm{C}$. Elemental iron.

Fig. 13. Effect of sintering temperature on sintered density. Fig. 14. Sintered density of elemental and prealloyed fe powders.

Fig. 15. Ultimate tensile strength of elemental and prealloyed Fe powder compacts. 
Fig. 16. Transverse rupture strength of elemental and prealloyed Fe powder compacts.

Fig. 17. EMP elemental Fe powder mixed with 30\% $\mathrm{Cu}-\mathrm{Mn}-\mathrm{Si}$ and sintered at $1050^{\circ} \mathrm{C}$ for 5 minutes and 4 hours. EDAX X-ray profile analysis of the three phases present.

Fig. 18. Microstructure of EMP elemental Fe powdex mixed with $30 \% \mathrm{Cu}-\mathrm{Mn}-\mathrm{Si}$ and sintered at $1050^{\circ} \mathrm{C}$ for 5 minutes.

Fig. 19. Microstructure of EMP elemental Fe powder mixed with $30 \% \mathrm{Cu}-\mathrm{Mn}-\mathrm{Si}$ and sintered at $1050^{\circ} \mathrm{C}$ for 4 hours. (a). 600x, (b). 150x. 


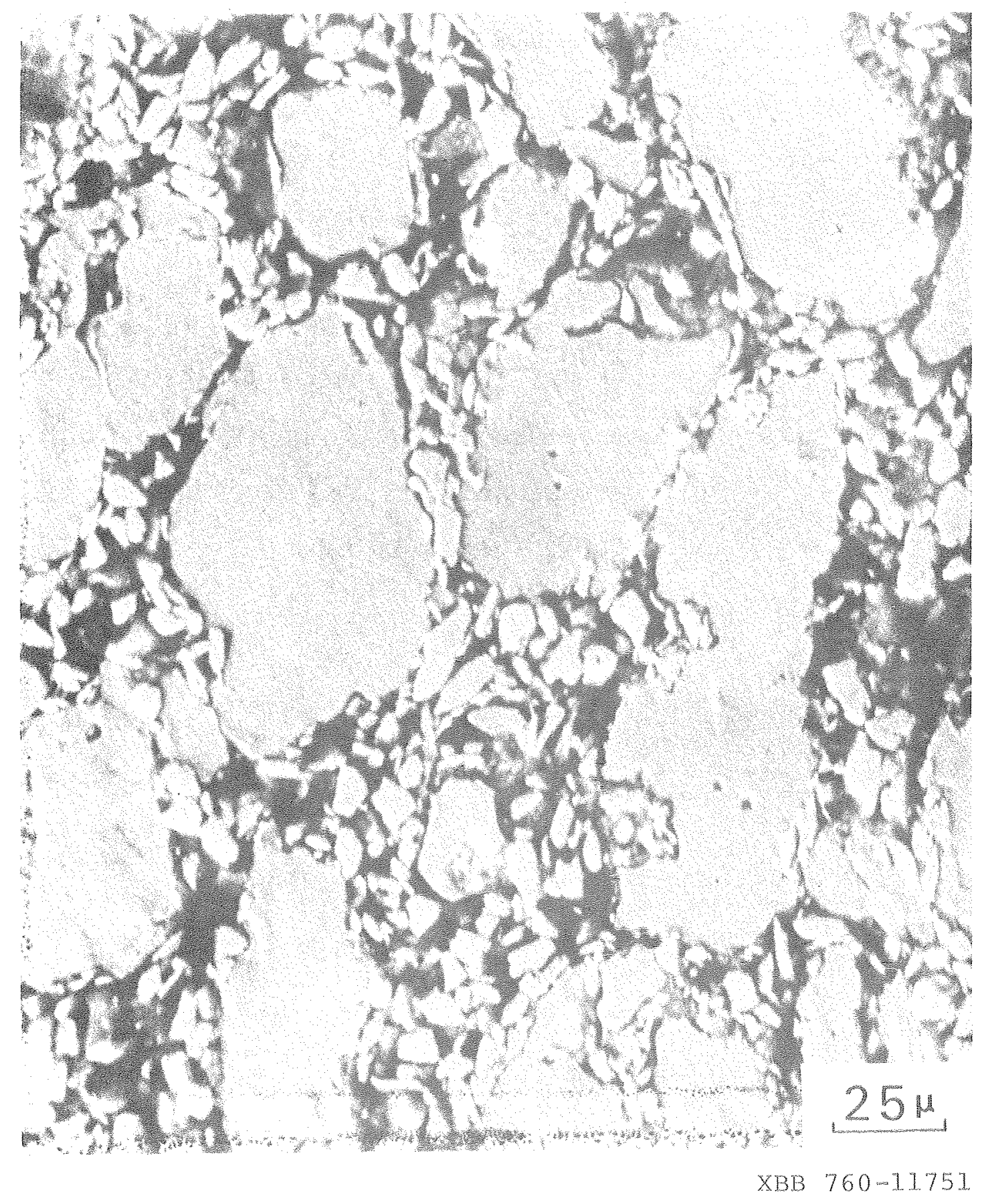

Fig. 1 


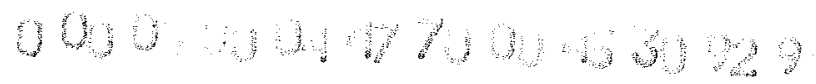

$-21=$

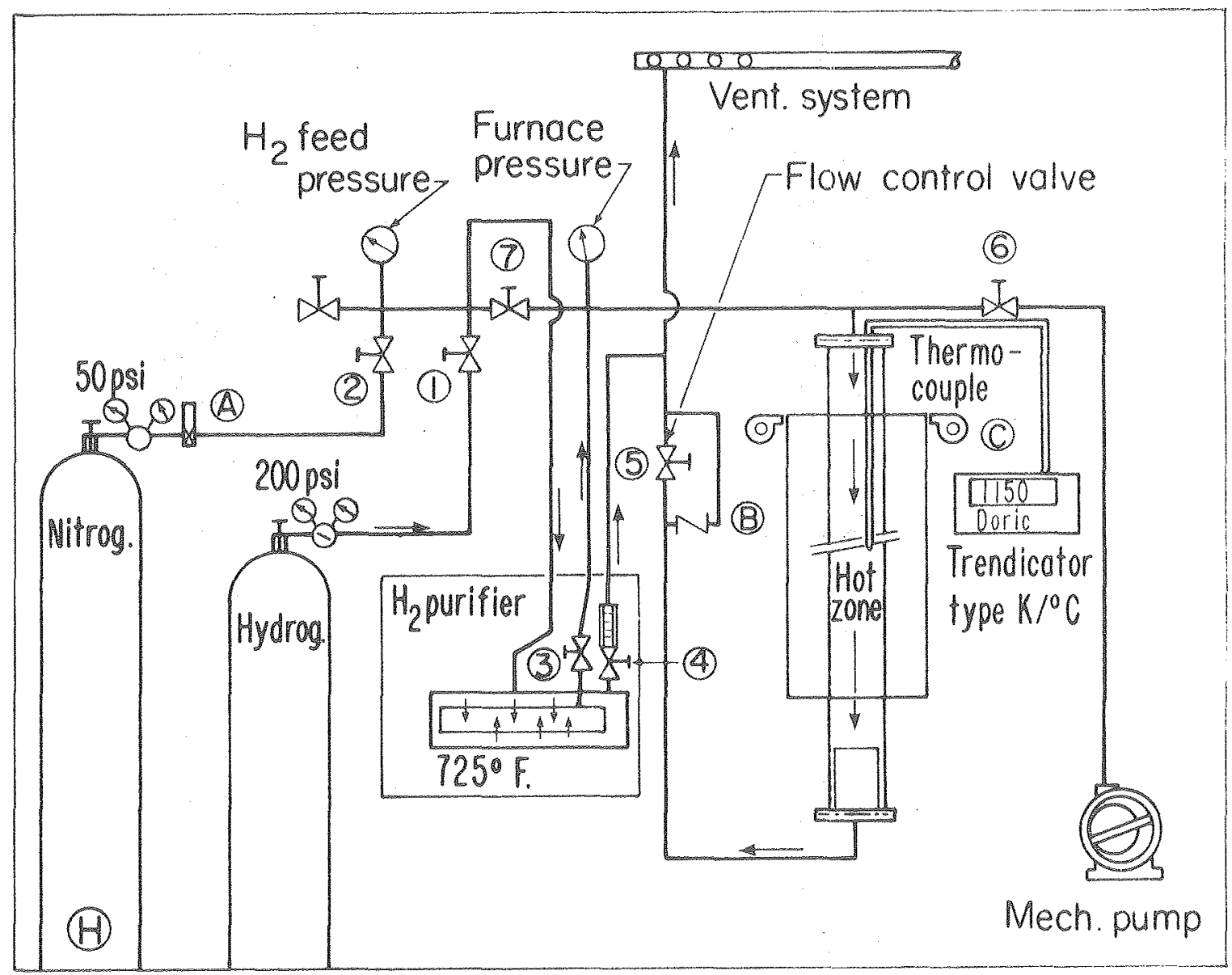

$X B L 772-355$

Fig. 2 


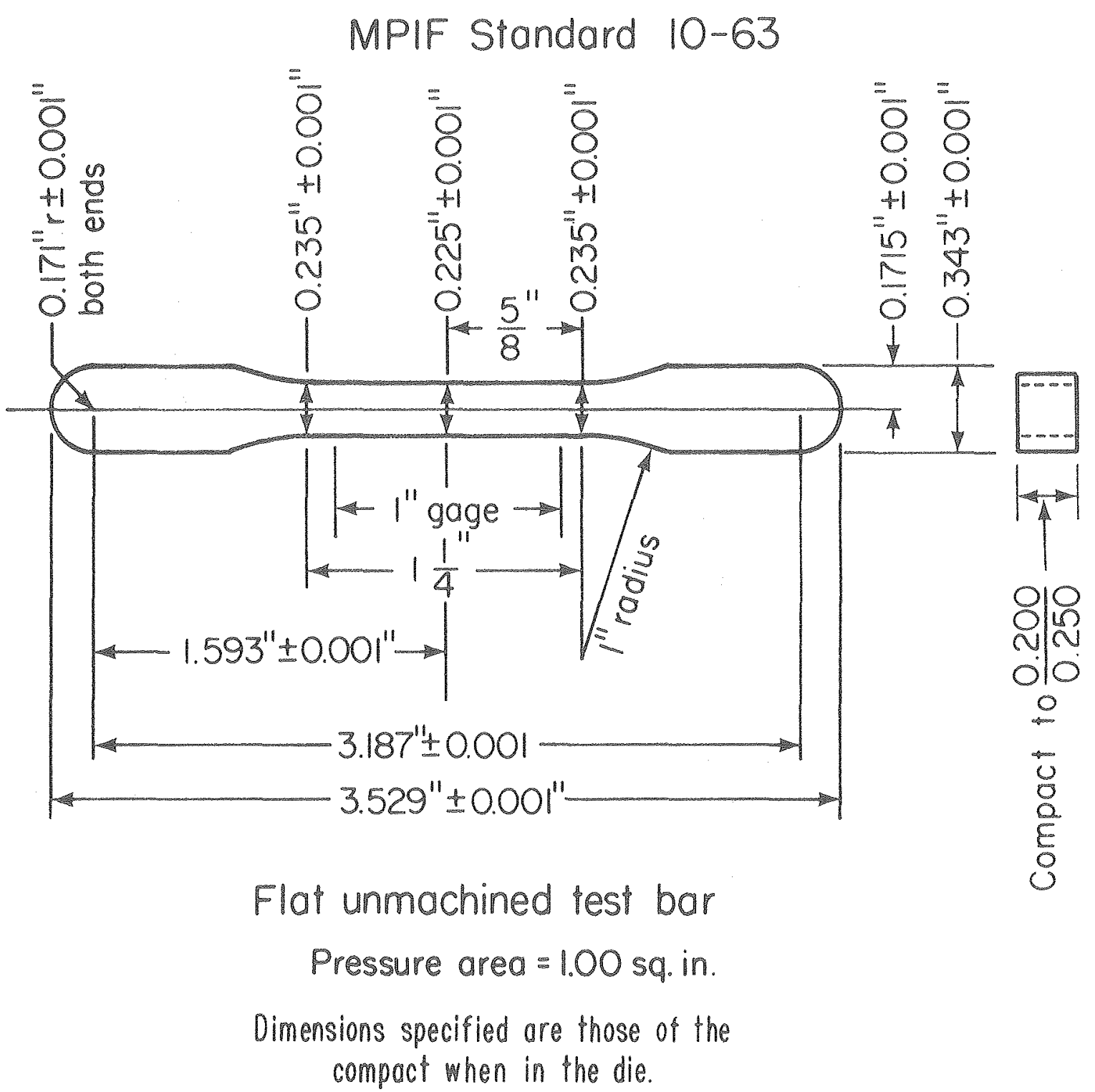

XBL772-356

Fig. 3 

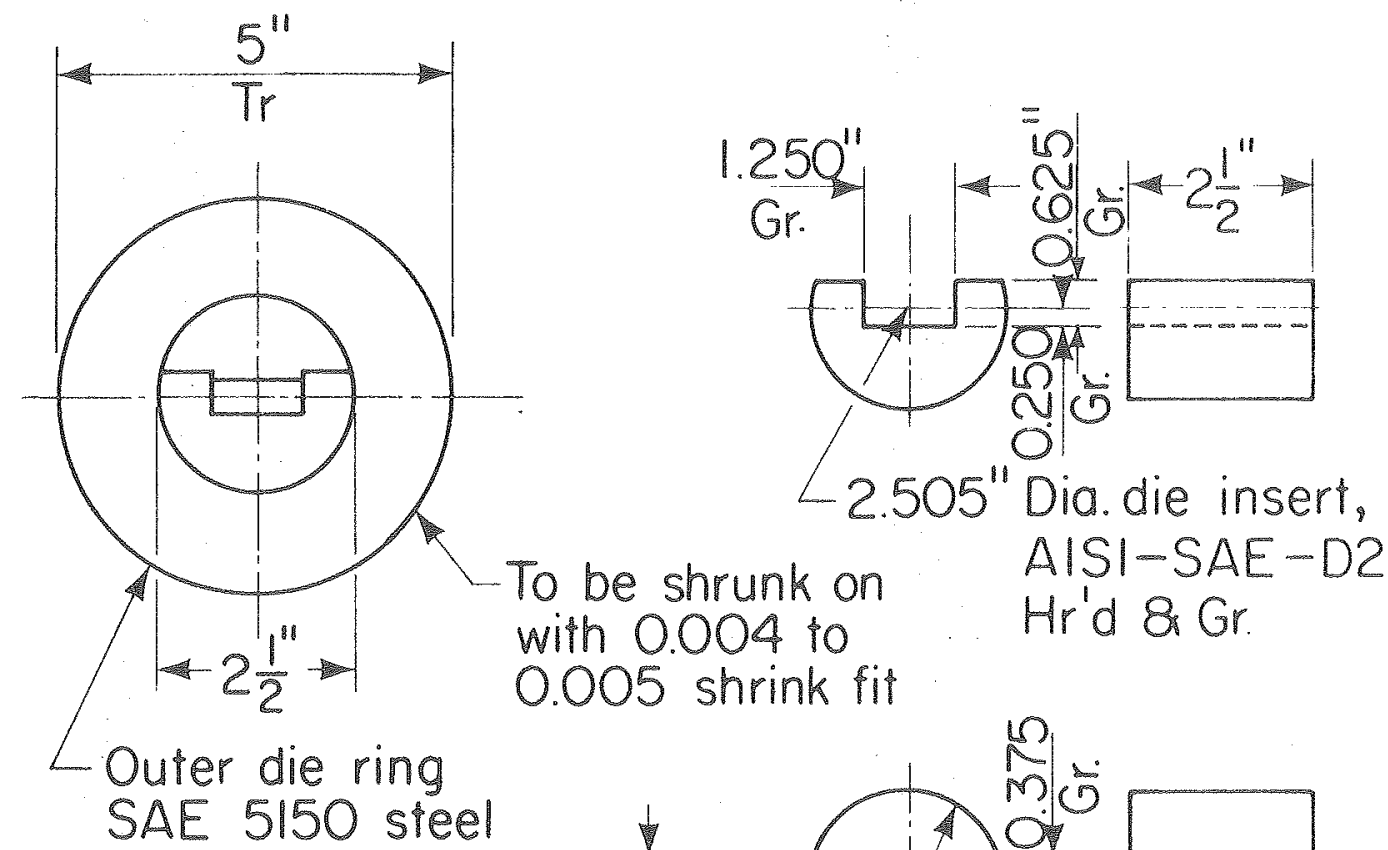

To be shrunk on with 0.004 to

AISI-SAE-D2 0.005 shrink fit $H r^{\prime} d 8 \mathrm{Gr}$
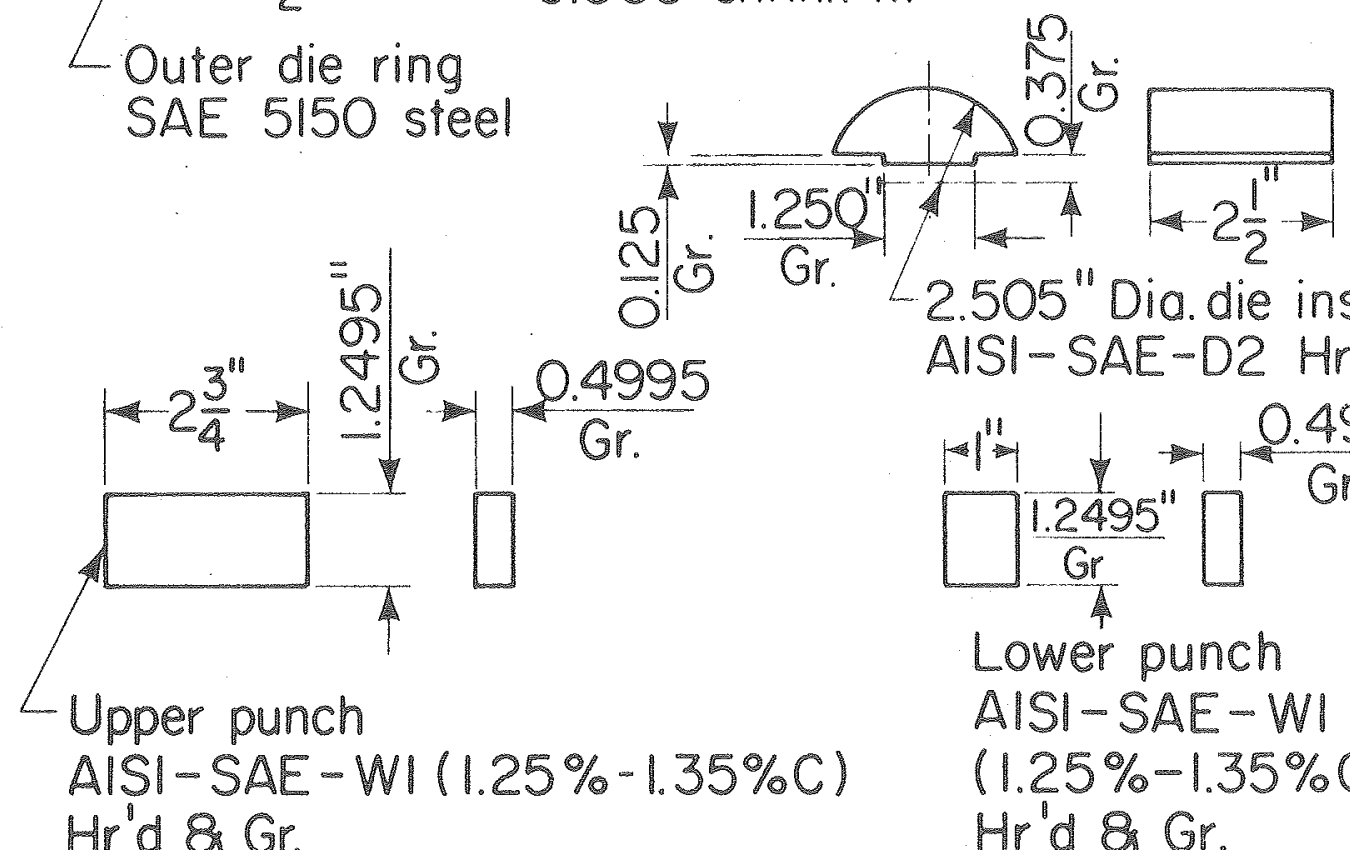
AISI-SAE-D2 Hr'd 8 Gr. $\square_{\text {Lower punch }}^{\frac{1.2495^{\prime \prime}}{4}} \square^{\mathrm{G} .4995^{\prime \prime}}$ AISI-SAE-WI $(1.25 \%-1.35 \% \mathrm{C})$ $\mathrm{Hr}^{\prime} \mathrm{d} \& \mathrm{Gr}$.

XBL $772-358$

Fig. 

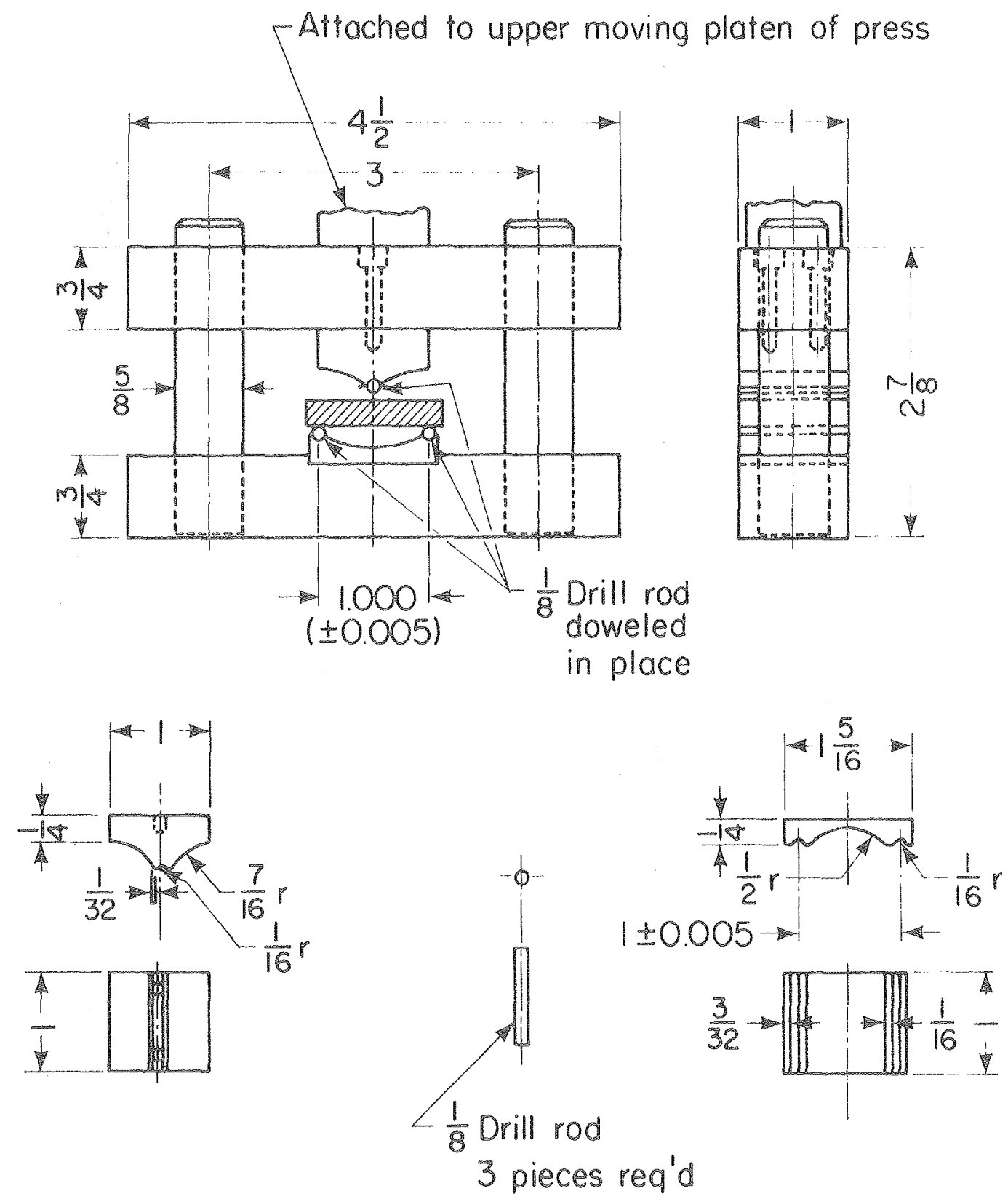

Details of fixture for testing bending strength All dimensions in inches. 

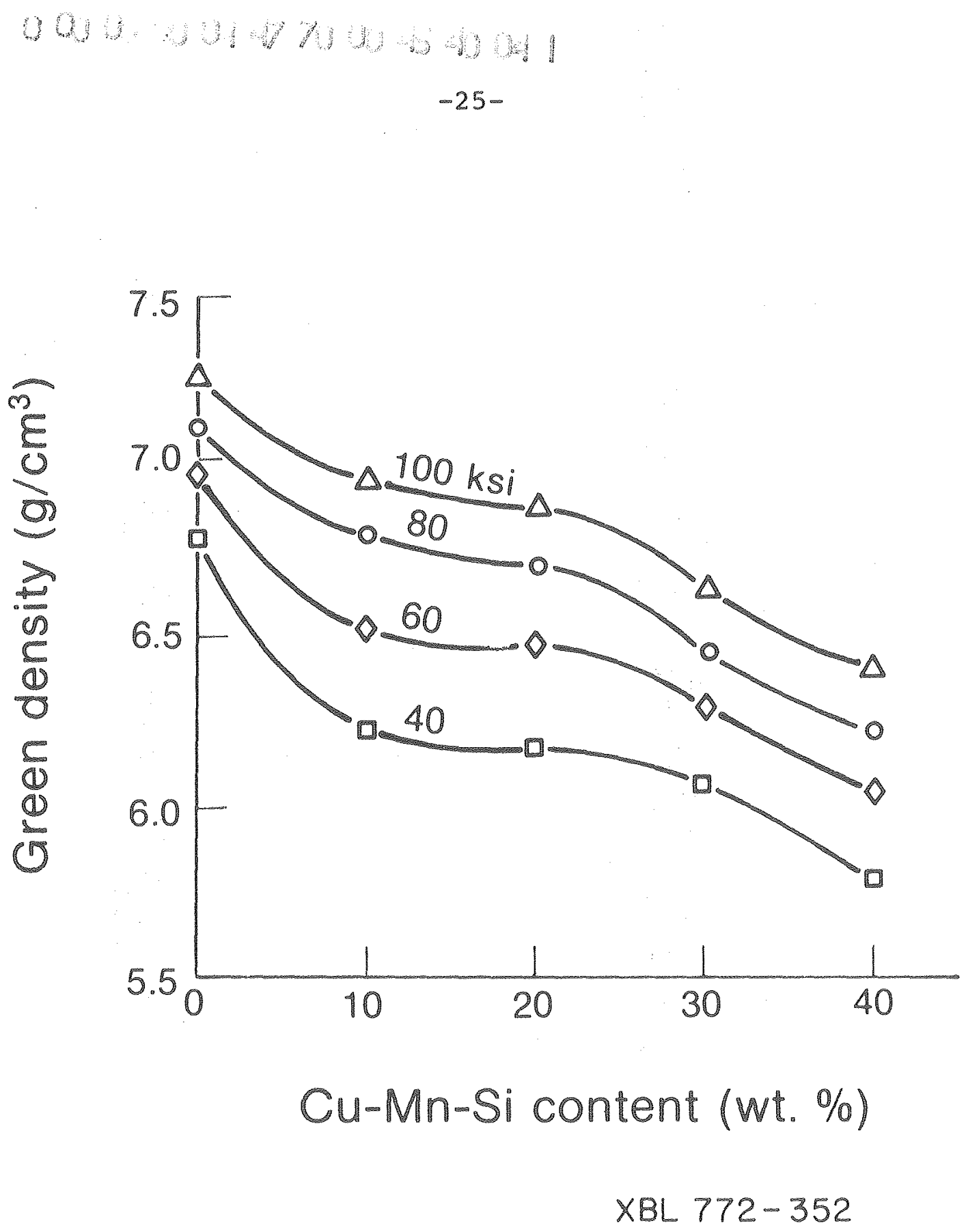

Fig. 6 


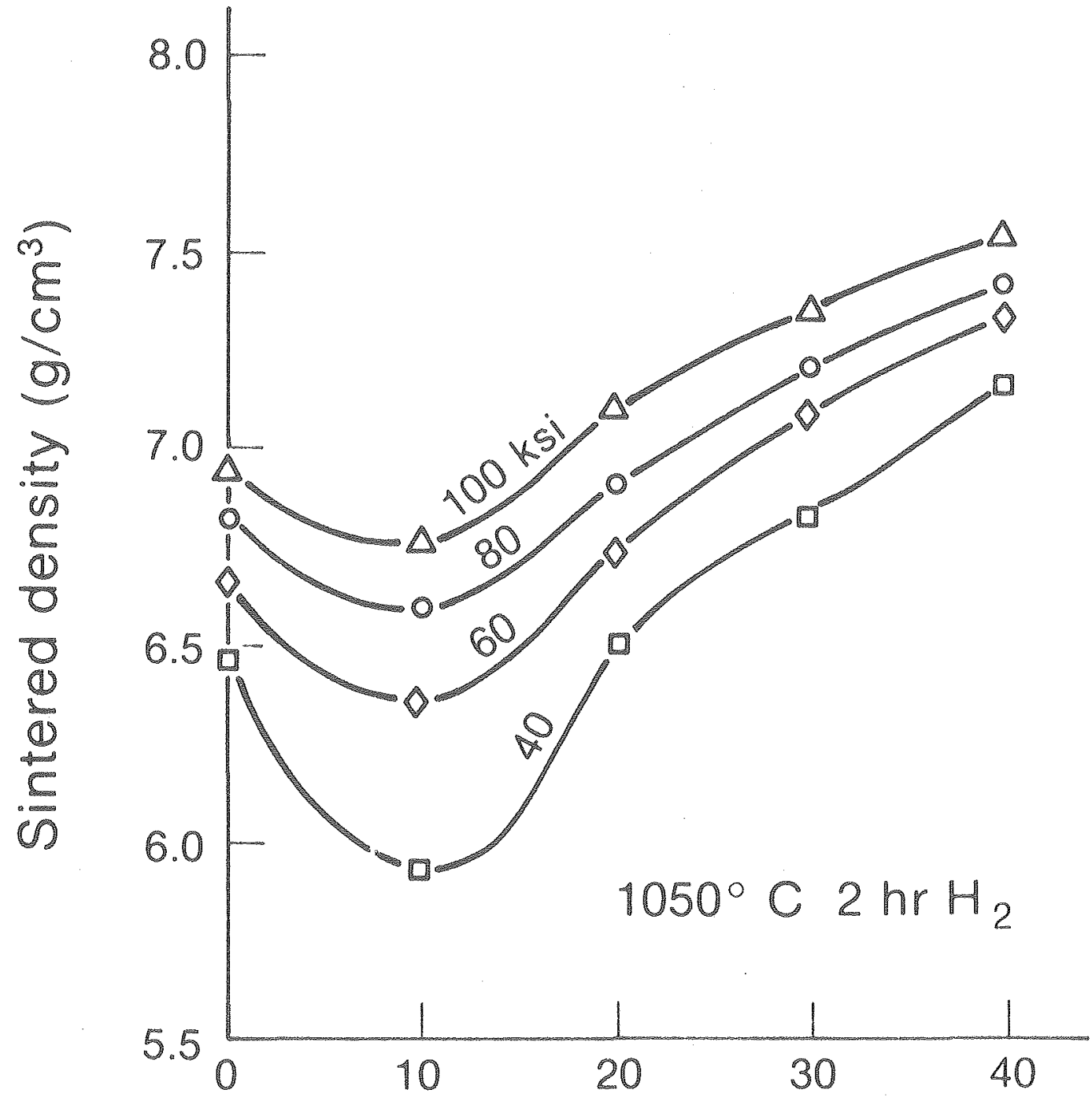

Cu-Mn-Si content (wt. \%)

XBL $772-349$

Fig. 7 


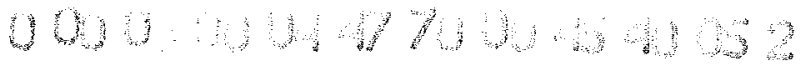 \\ $-27-$}

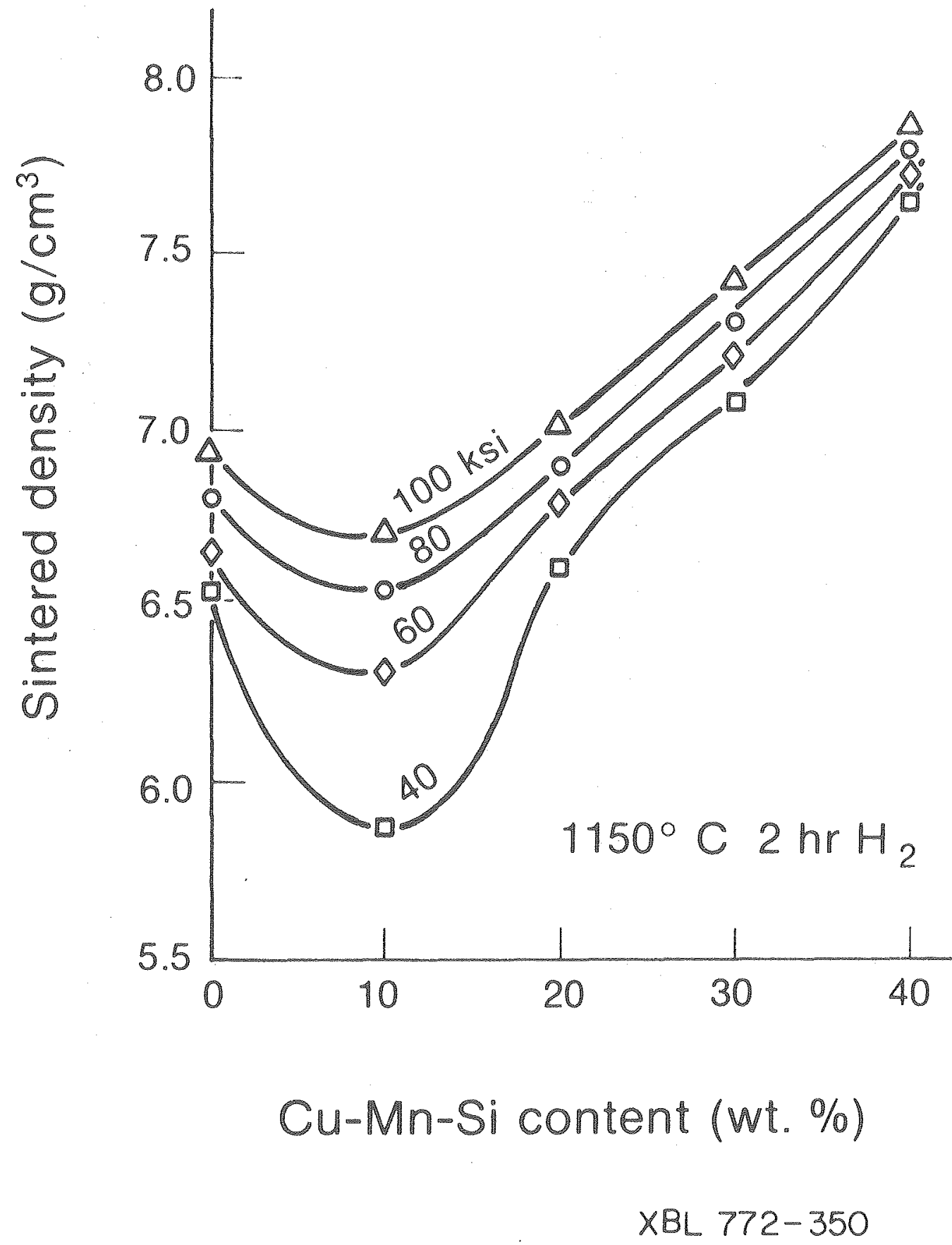

Fig. 8 


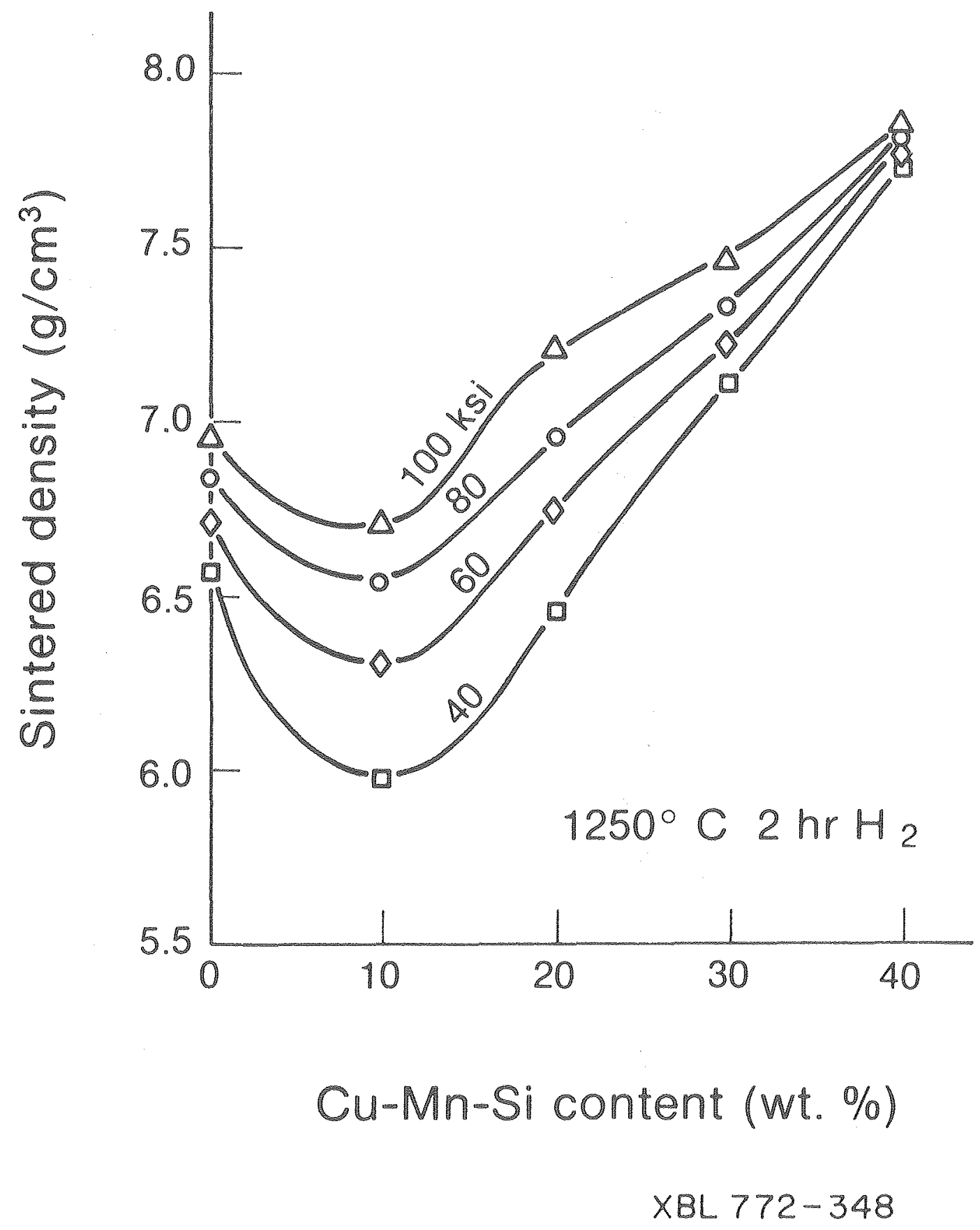

Fig. 9 


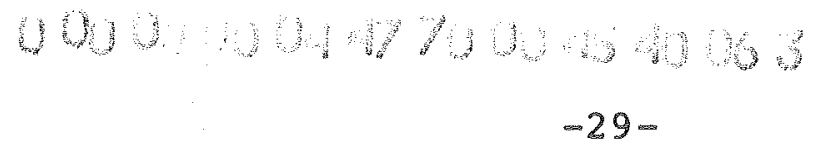

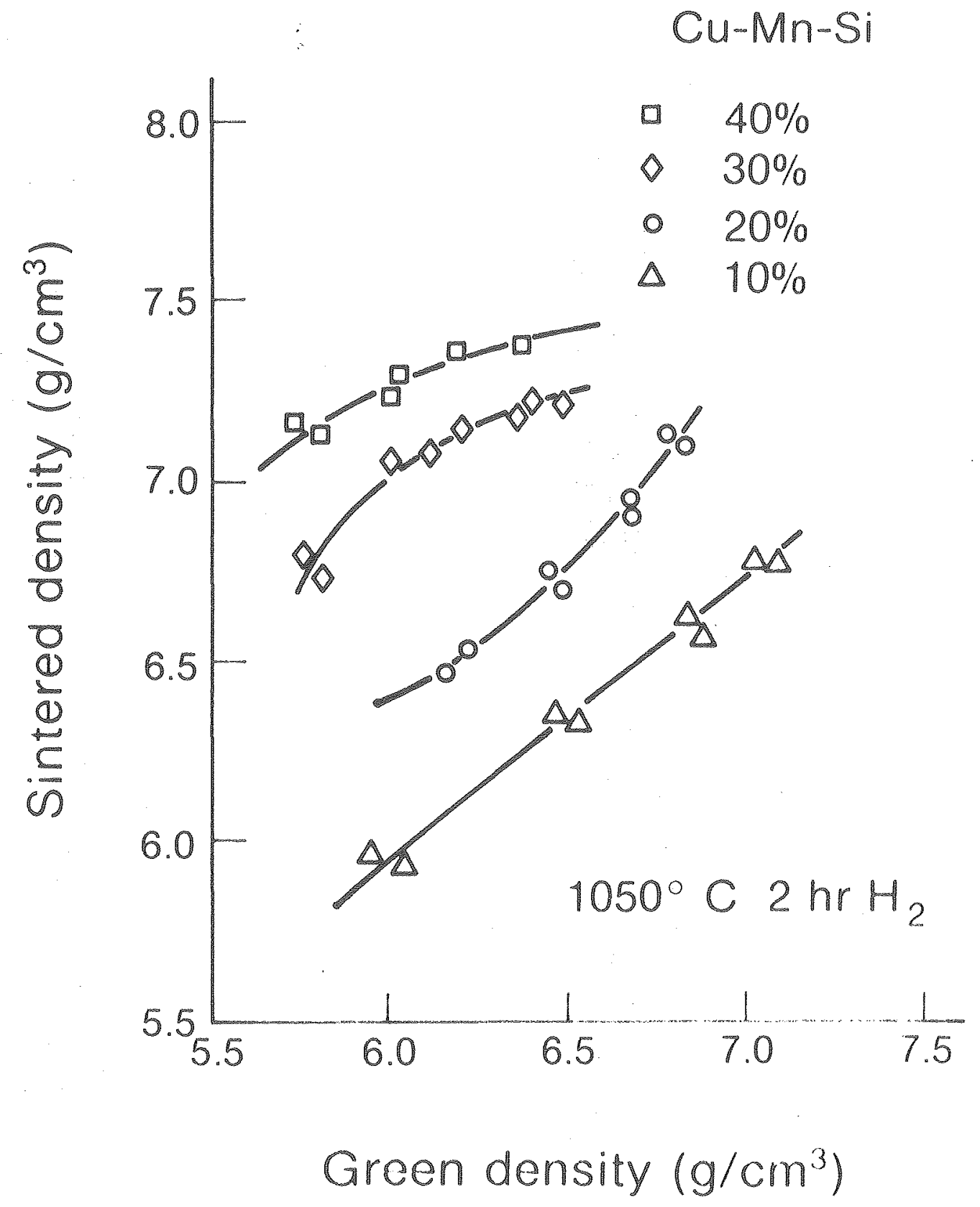

XBL $772-344$

Fig. 10 


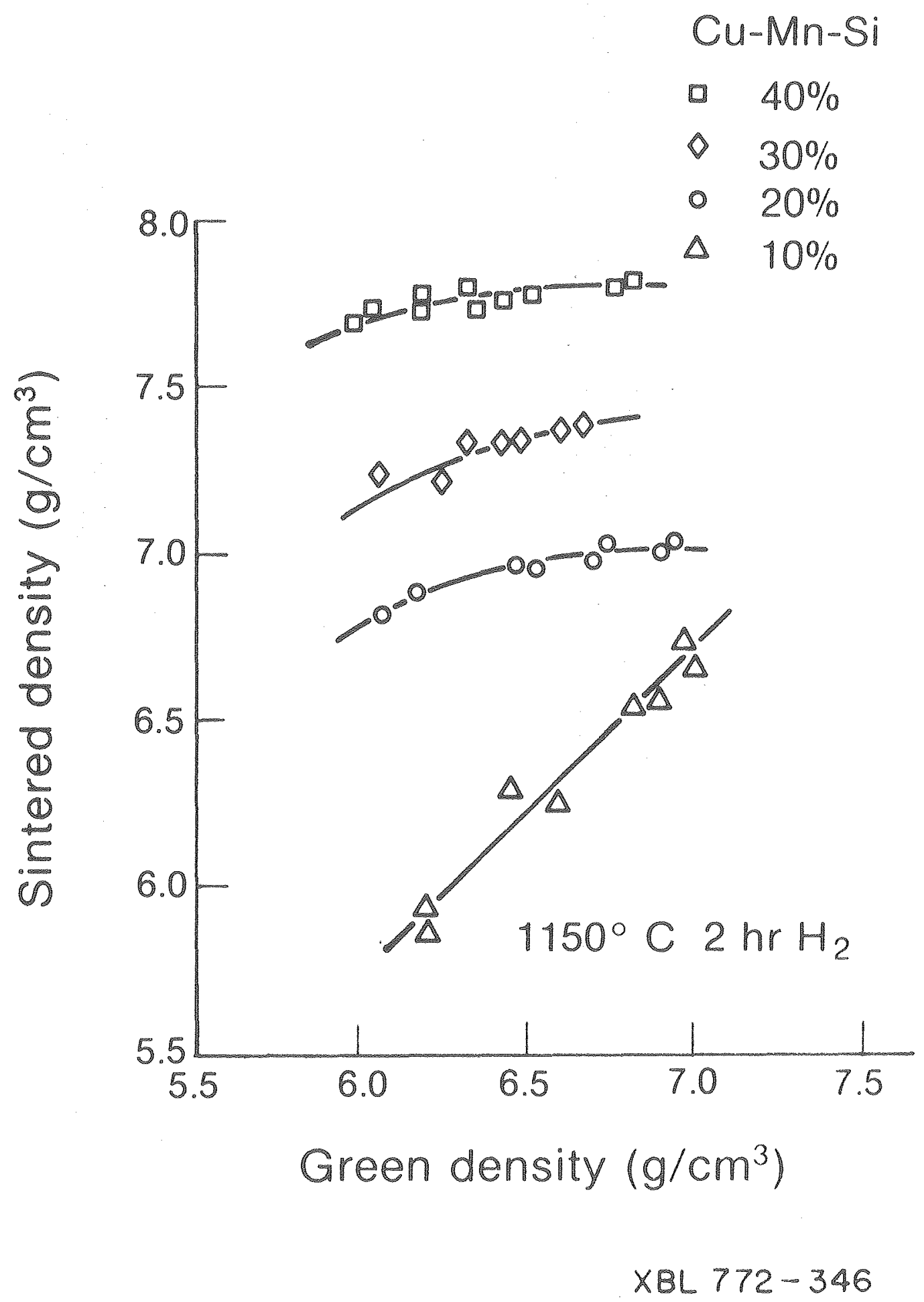

Fig. 11 


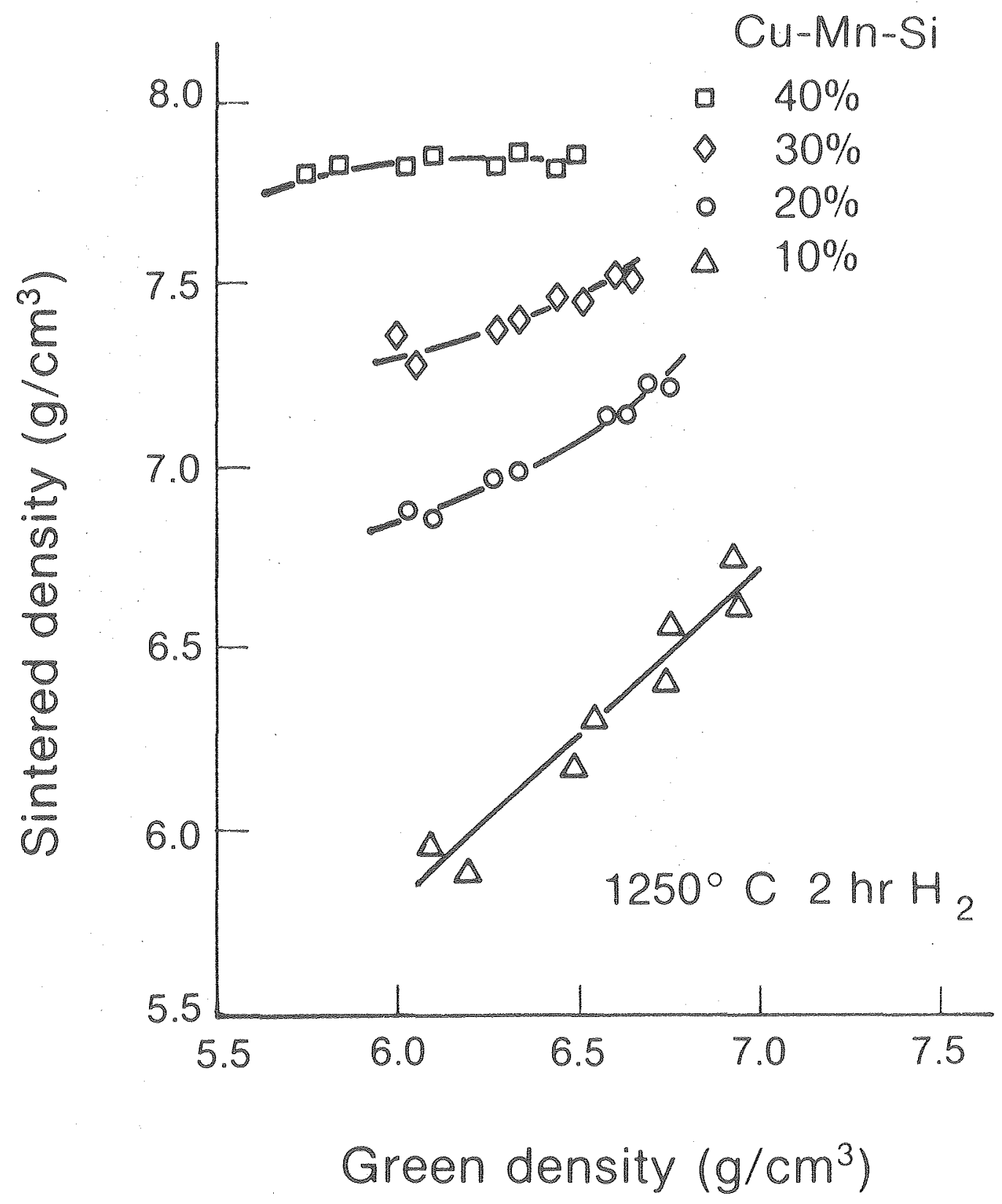

XBL $772-345$

Fig. 12 


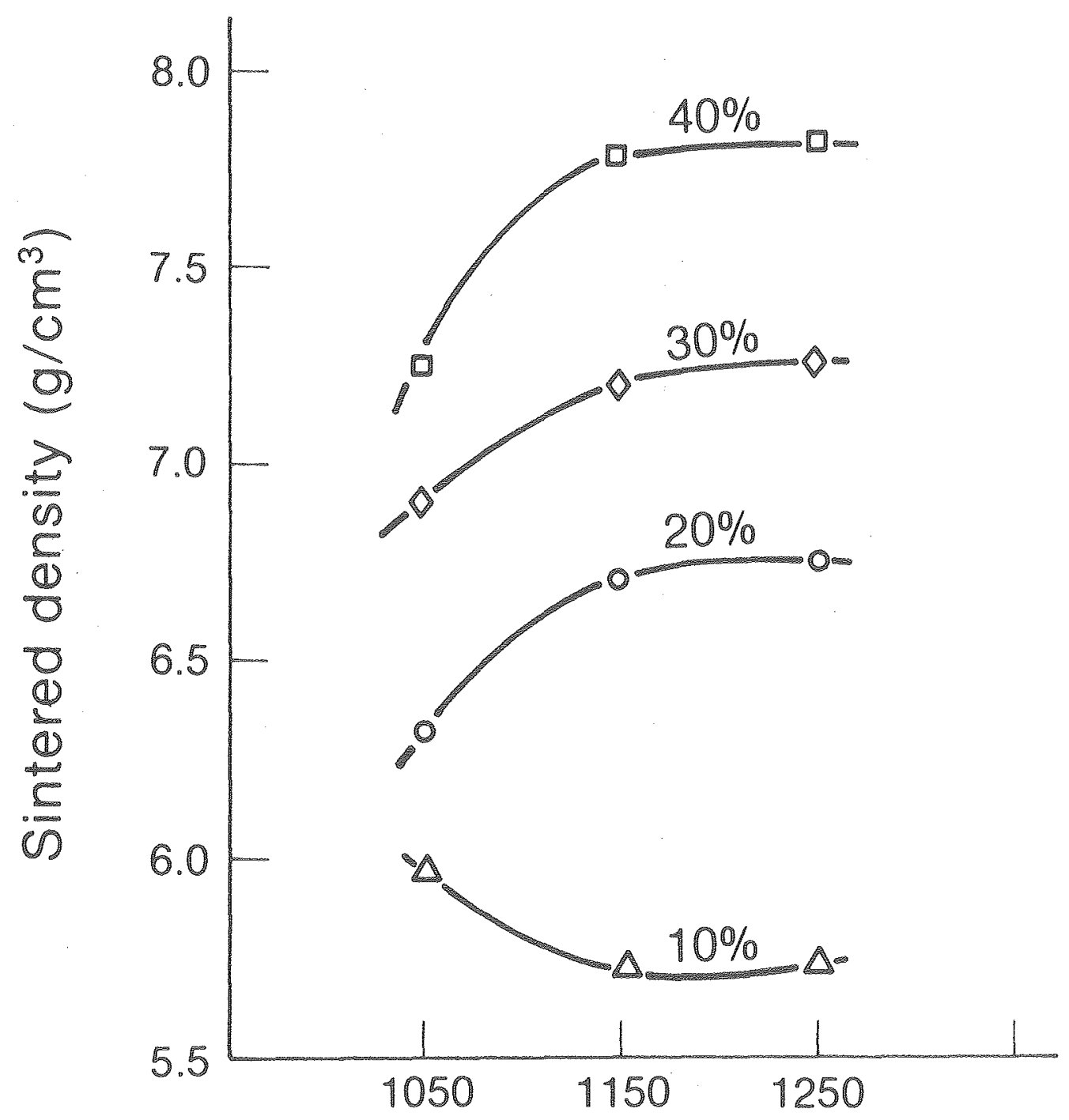

Sintering temperature $\left({ }^{\circ} \mathrm{C}\right)$

XBL $772-351$

Fig. 13 


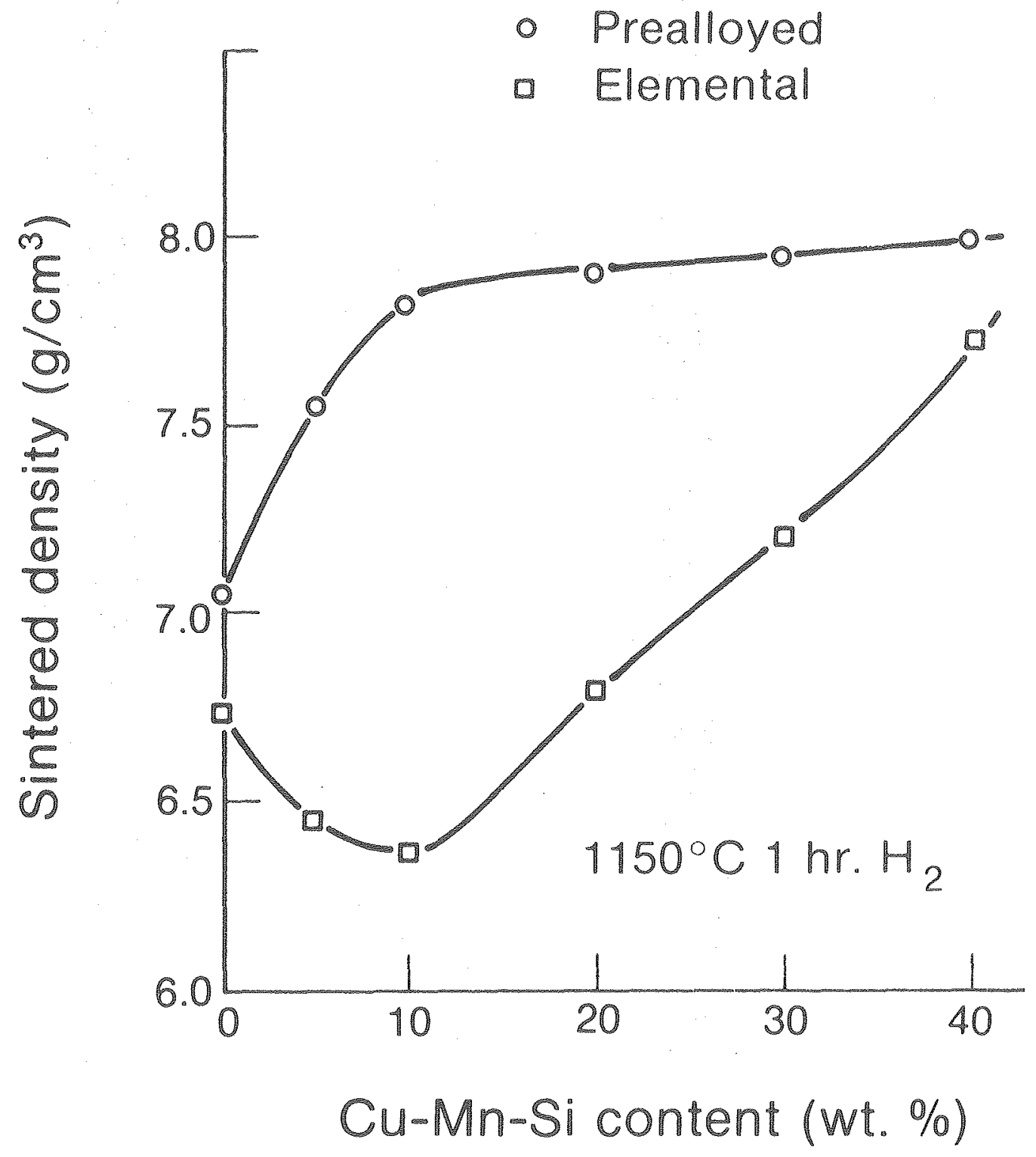

XBL $772-347$

Fig. 14 


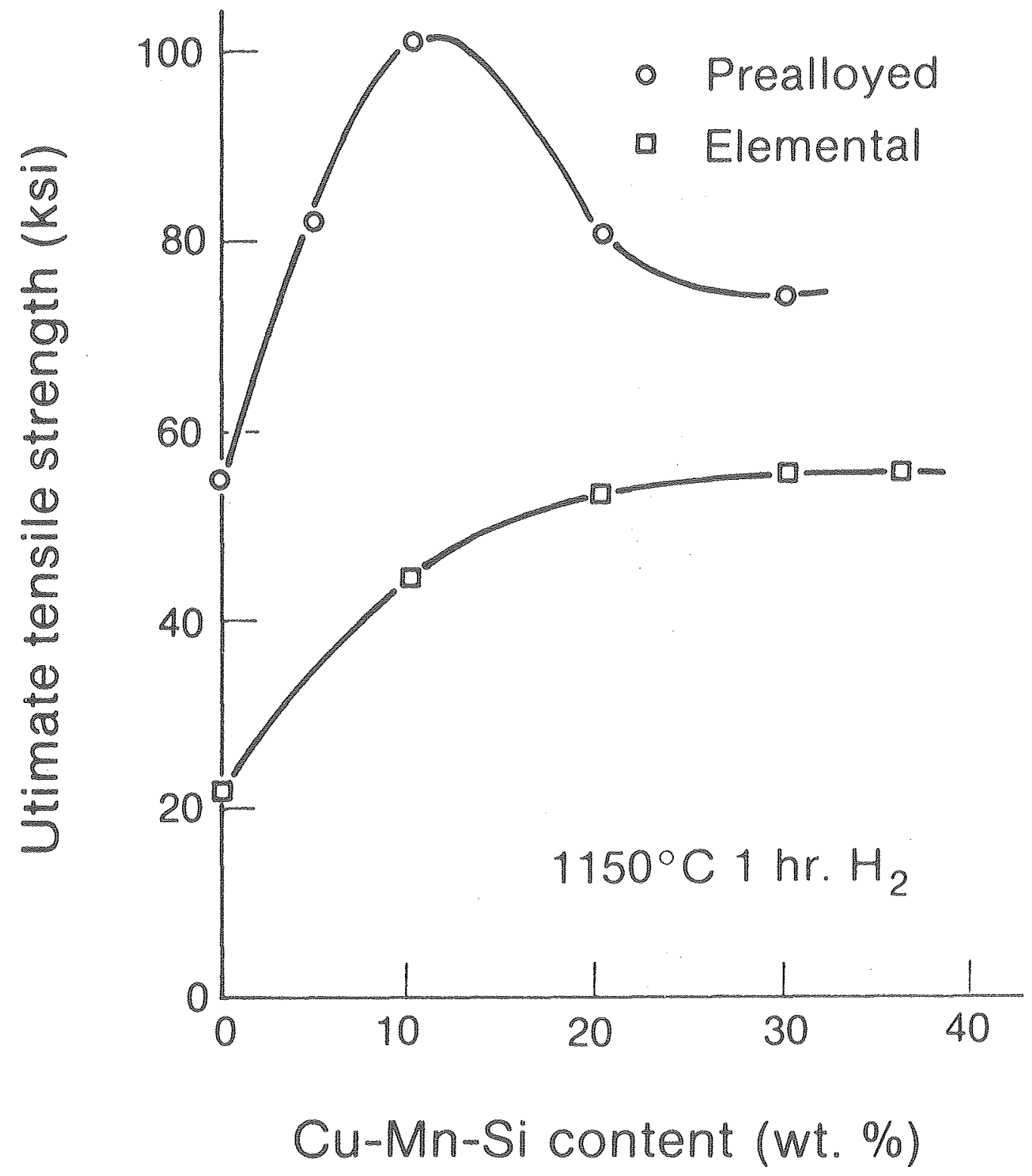

XBL772-354

Fig. 15 


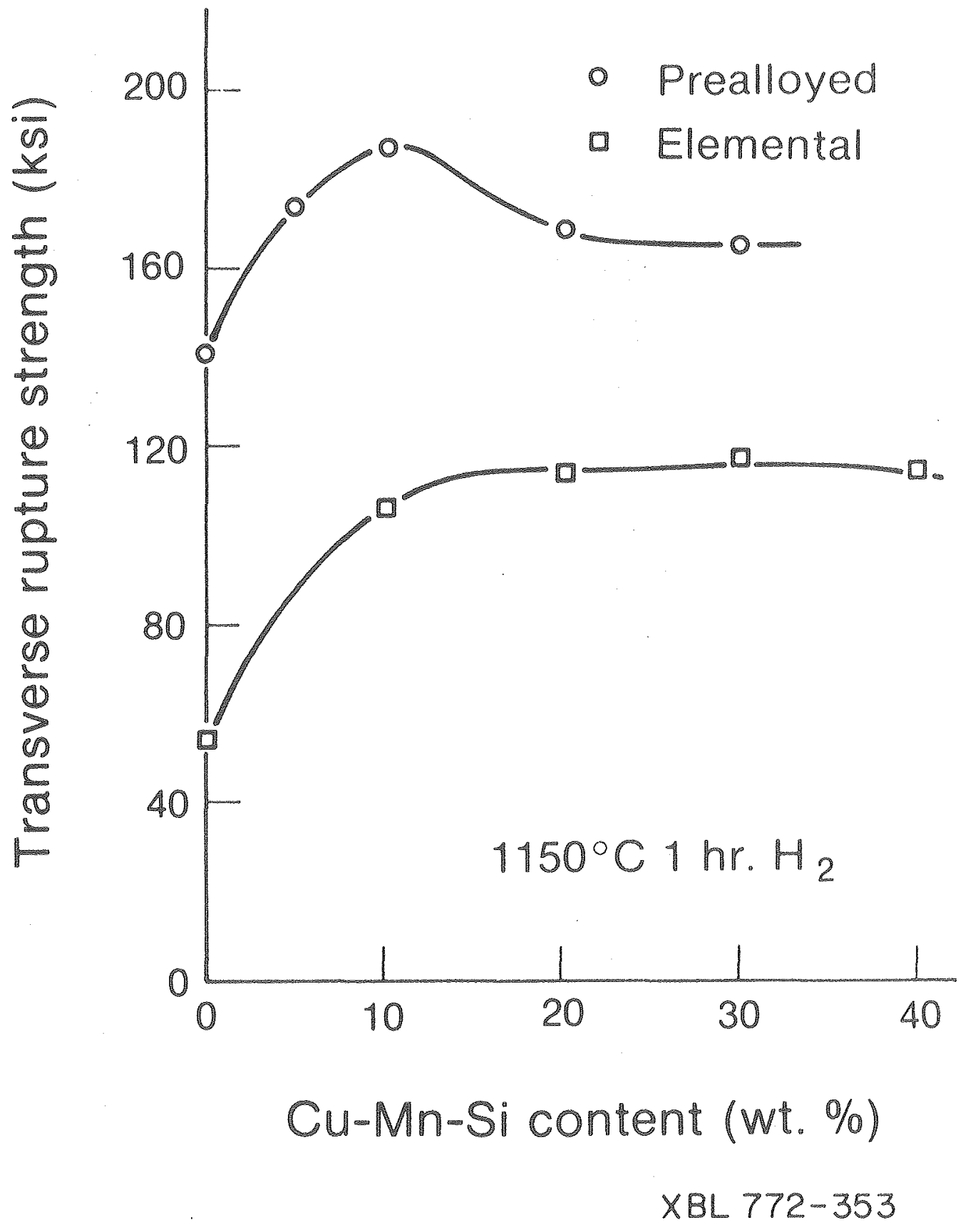

Fig. 16 

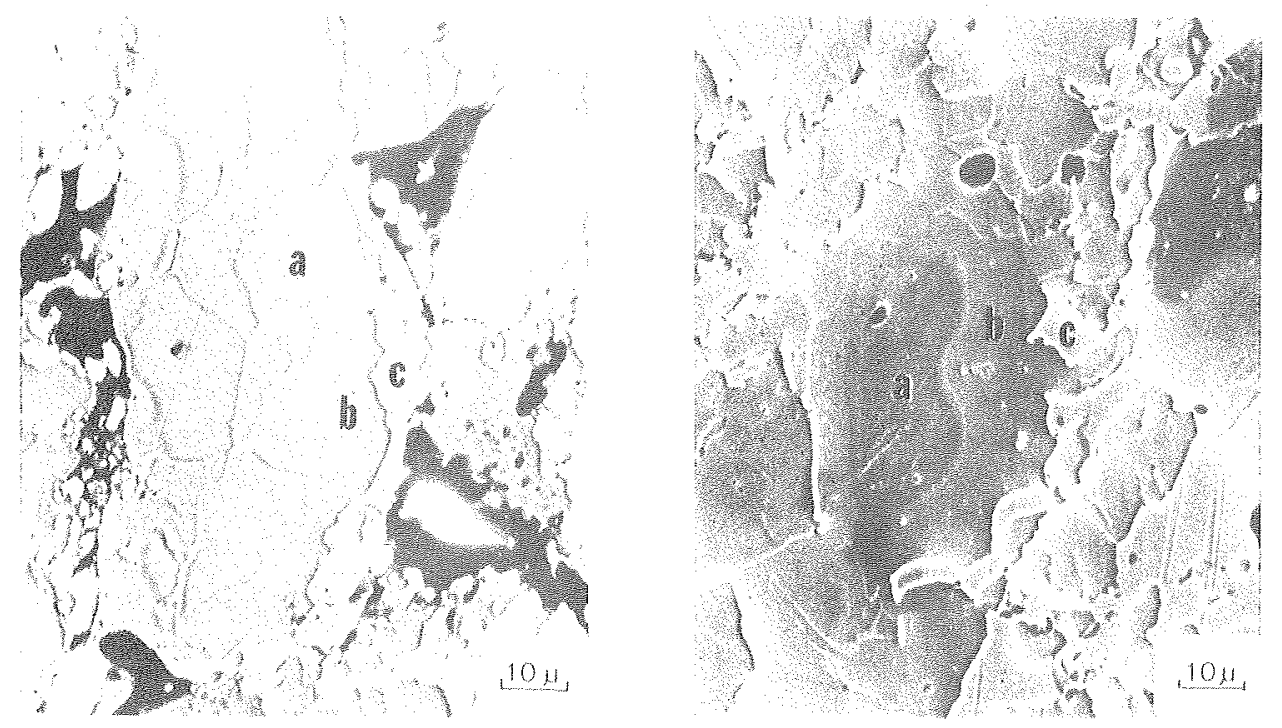

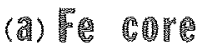

$\begin{array}{cc}\text { Fe } & 97.3 \\ \text { Cu } & 0.1 \\ \text { Mn } & 0.2 \\ \text { Si } & 2.4 \\ \text { VH } & 120\end{array}$

(最) 团最:

Fe 88.3

Cu 2.9

Mn 2.1

Si 6.1

VH 420
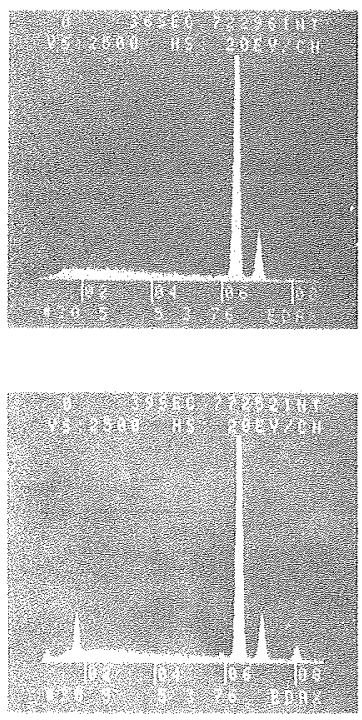

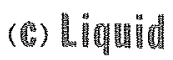

$\begin{array}{cr}\text { Fe } & 4.4 \\ \text { Cu } & 91.4 \\ \text { Mn } & 4.1 \\ \text { Si } & 0.1 \\ \text { VH } & 106\end{array}$

$\mathrm{Fe} \quad 4.4$

Cu 91.4

Mn 4.1

VH 106

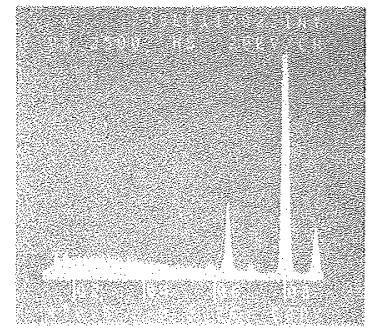

EMP- $-30 \% \mathrm{Cu} \cdot \mathrm{Mn}-\mathrm{Si}$

$5 \min 1050^{\circ} \mathrm{C} \mathrm{Hz}$ (a) Tracte

Fe 960

Cu 0.1

Mn 0.3

Si 3.6

VH 160

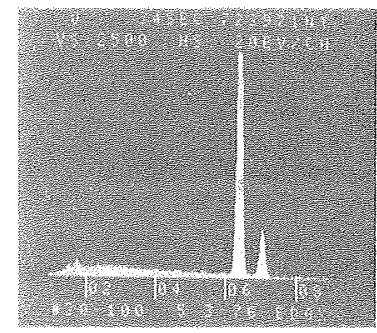

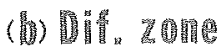

Fe 89.8

Cu 4.4

Mn 2.3

Si 4.5

VH 460

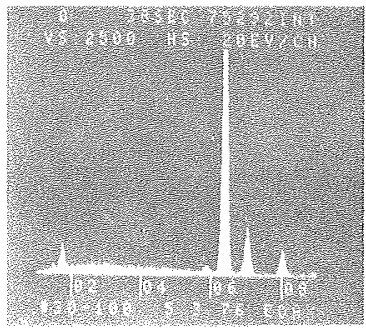

(6) Lingund

Fe 3.4

Cu 92.0

$\mathrm{Mn} \quad 4.5$

Si 0.1

VH 95

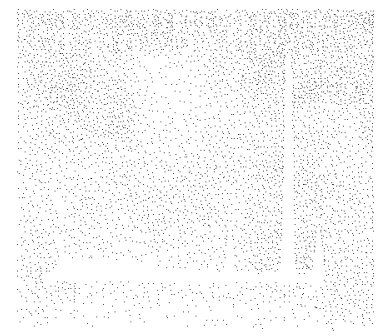

EMP- $30 \%$ CUMn-Si

4 hr. $1050^{\circ} \mathrm{C} \mathrm{H}$

XBB $\quad 760-11752$ 


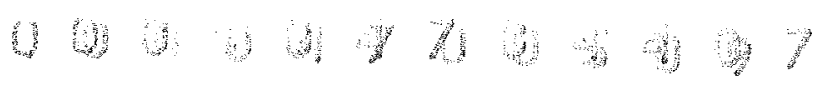

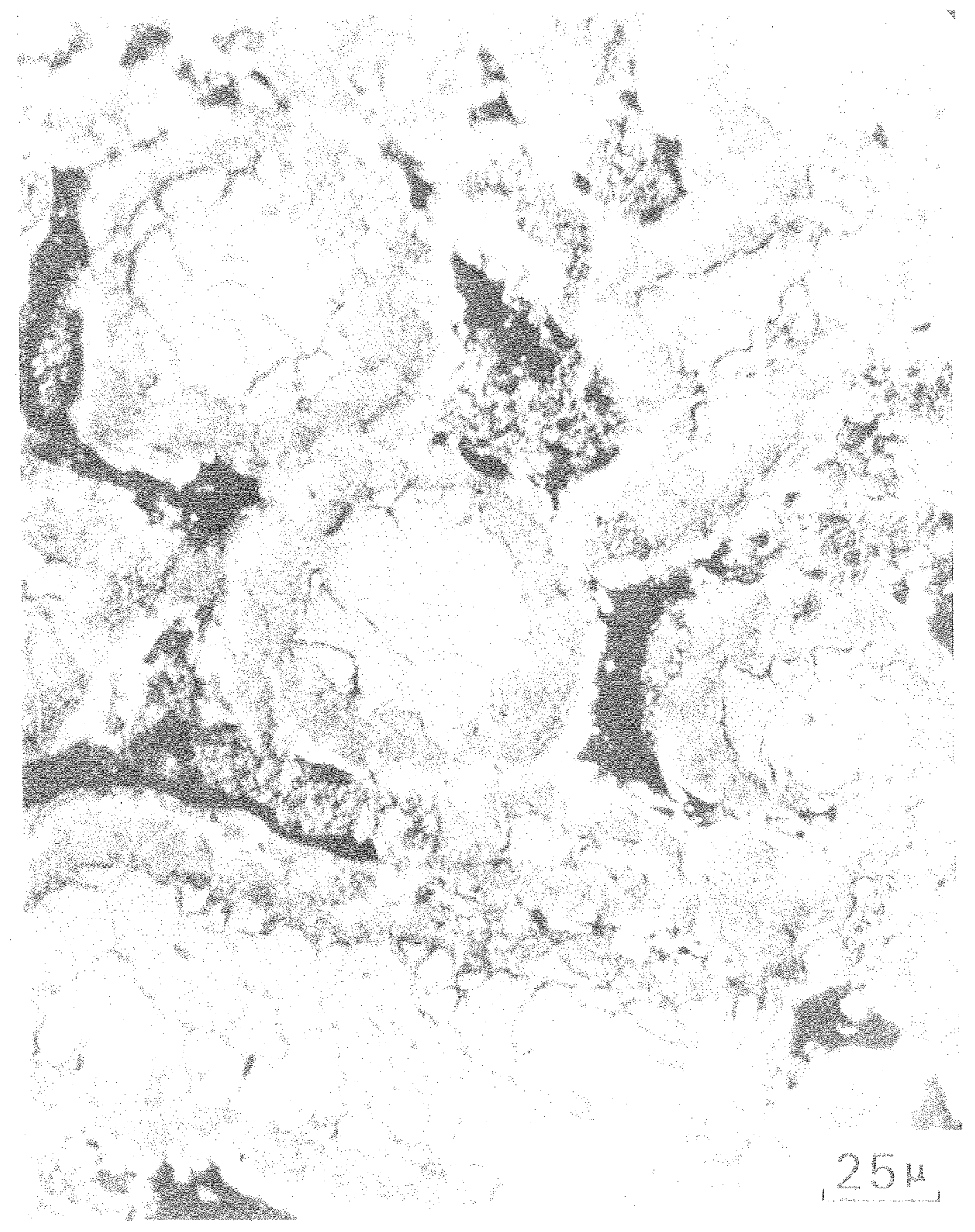

XBB $760-11750$ 

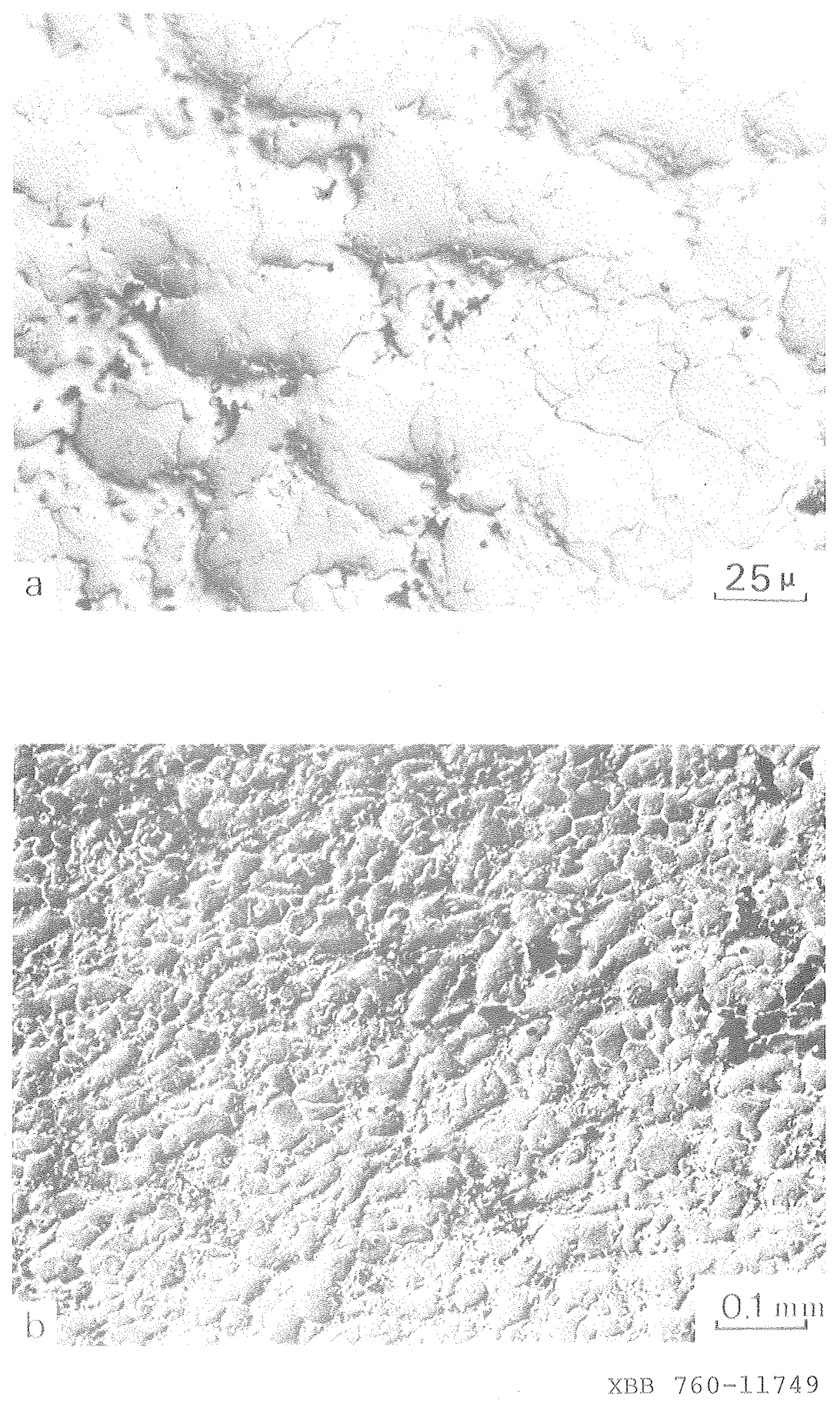

Fig. 19 
This report was done with support from the United States Energy Research and Development Administration. Any conclusions or opinions expressed in this report represent solely those of the author(s) and not necessarily those of The Regents of the University of California, the Lawrence Berkeley Laboratory or the United States Energy Research and Development Administration. 